\title{
Novel 1-hydroxypyridin-2-one metal chelators prevent and rescue ubiquitin proteasomal-related neuronal injury in an in vitro model of Parkinson's disease
}

\author{
Frank W. Lewis ${ }^{1}$. Safiya Fairooz ${ }^{1}$. Joanna L. Elson ${ }^{2}$. Véronique Hubscher-Bruder ${ }^{3}$. Jeremy Brandel ${ }^{3}$. \\ Meera Soundararajan ${ }^{1} \cdot$ David Smith $^{4} \cdot$ David T. Dexter $^{5} \cdot$ David Tétard $^{1} \cdot$ Ilse S. Pienaar ${ }^{6}$ (i)
}

Received: 28 August 2019 / Accepted: 11 February 2020 / Published online: 20 February 2020

(c) The Author(s) 2020

\begin{abstract}
Ubiquitin proteasome system (UPS) impairment, excessive cellular oxidative stress, and iron dyshomeostasis are key to substantia nigra dopaminergic neuronal degeneration in Parkinson's disease (PD); however, a link between these features remains unconfirmed. Using the proteasome inhibitor lactacystin we confirm that nigral injury via UPS impairment disrupts iron homeostasis, in turn increasing oxidative stress and promoting protein aggregation. We demonstrate the neuroprotective potential of two novel 1-hydroxy-2(1H)-pyridinone (1,2-HOPO) iron chelators, compounds $\mathrm{C} 6$ and $\mathrm{C} 9$, against lactacystininduced cell death. We demonstrate that this cellular preservation relates to the compounds' iron chelating capabilities and subsequent reduced capacity of iron to form reactive oxygen species (ROS), where we also show that the ligands act as antioxidant agents. Our results also demonstrate the ability of C6 and C9 to reduce intracellular lactacystin-induced $\alpha$-synuclein burden. Stability constant measurements confirmed a high affinity of C6 and C9 for $\mathrm{Fe}^{3+}$ and display a 3:1 HOPO:Fe ${ }^{3+}$ complex formation at physiological $\mathrm{pH}$. Reducing iron reactivity could prevent the demise of nigral dopaminergic neurons. We provide evidence that the lactacystin model presents with several neuropathological hallmarks of PD related to iron dyshomeostasis and that the novel chelating compounds C6 and C9 can protect against lactacystin-related neurotoxicity.
\end{abstract}

Keywords Alpha-synuclein · Dopaminergic $\cdot$ Iron chelators $\cdot$ Lactacystin $\cdot$ Parkinson's disease $\cdot$ Reactive oxygen species

David Tétard and Ilse S. Pienaar have equal authorship.

David Tétard

david.tetard@northumbria.ac.uk

Ilse S. Pienaar

I.S.Pienaar@sussex.ac.uk

1 Department of Applied Sciences, Faculty of Health and Life Sciences, Northumbria University, Newcastle upon Tyne NE1 8ST, UK

2 Institute of Genetic Medicine, Newcastle University, Newcastle upon Tyne NE1 3BZ, UK

3 Hubert Curien Pluridisciplinary Institute (IPHC), Université de Strasbourg, 67087 Strasbourg, France

4 Department of Biosciences and Chemistry, Sheffield Hallam University, Sheffield, UK

5 Centre for Neuroinflammation and Neurodegeneration, Faculty of Medicine, Imperial College London, London W12 ONN, UK

6 School of Life Sciences, University of Sussex, Falmer BN1 9PH, UK

\begin{tabular}{ll}
\multicolumn{2}{l}{ Abbreviations } \\
A $\beta$ & Amyloid $\beta$-peptide \\
$\alpha-$ SYN & $\alpha$-Synuclein \\
C & Compound \\
DFP & Deferiprone \\
DDA & Deoxyribose degradation assay \\
DFO & Desferoxamine \\
DHR & Dihydrorhodamine \\
DMSO & Dimethyl sulfoxide \\
DPPH & 2,2-Diphenyl-1-picrylhydrazyl \\
DMT1 & Divalent metal transporter 1 \\
DAergic & Dopaminergic \\
DMEM & Dulbecco's Modified Eagle's medium \\
UV & Ultraviolet \\
EDTA & Ethylenediaminetetra-acetic acid \\
eROS & Extracellular ROS \\
FT & Ferritin \\
FPN & Ferroportin \\
TfR & Transferrin \\
FBS & Foetal bovine serum \\
GLEE & Glass electrode evaluation
\end{tabular}




$\begin{array}{ll}\text { Hepc } & \text { Hepatocyte-secreted hormone } \\ \text { HEPES } & \begin{array}{l}\text { 4-(2-Hydroxyethyl)-1-piperazineethanesul- } \\ \text { fonic acid }\end{array} \\ \text { HOPO } & \text { Hydroxypyridinone } \\ \text { 1,2-HOPO } & \text { 1-Hydroxypyridin-2-one } \\ \text { HRP } & \text { Horseradish peroxidase } \\ \text { ICP-MS } & \text { Inductively-coupled-plasma mass } \\ & \text { spectroscopy } \\ \text { iROS } & \text { Intracellular ROS } \\ \text { IRP2 } & \text { Iron regulatory protein 2 } \\ \text { LBs } & \text { Lewy bodies } \\ \text { LMCT } & \text { Ligand to metal charge transfer band } \\ \text { MS } & \text { Mass spectrometry } \\ \text { MFI } & \text { Mean fluorescence intensity } \\ \text { MTS } & \text { (3-(4,5-Dimethylthiazol-2yl)-5-(3- } \\ & \text { carboxymethoxyphenyl)-2-(4-sulfophenyl)- } \\ \text { Mfrn2 } & \text { 2H-tetrazolium } \\ \text { NMR } & \text { Mitoferrin-2 } \\ \text { PD } & \text { Nuclear magnetic resonance } \\ \text { ppm } & \text { Parkinson's disease } \\ \text { PBS } & \text { Phosphate-buffered saline } \\ \text { PAGE } & \text { Polyacrylamide gel electrophoresis } \\ \text { PVDF } & \text { Polyvinylidene difluoride } \\ \text { RIPA } & \text { Radioimmunoprecipitation assay } \\ \text { ROS } & \text { Reactive oxygen species } \\ \text { RT } & \text { Room temperature } \\ \text { RPM } & \text { Rotations per minute } \\ \text { 6-OHDA } & \text { 6-Hydroxydopamine } \\ \text { SDS } & \text { Sodium dodecyl sulfate } \\ \text { SD } & \text { Standard deviation } \\ \text { SN } & \text { Substantia nigra } \\ \text { SNpc } & \text { Substantia nigra pars compacta } \\ \text { TBA } & \text { Thiobarbituric acid } \\ \text { UPS } & \text { Ubiquitin proteasome system } \\ \text { UV } & \text { Ultraviolet } \\ & \\ & \end{array}$

\section{Introduction}

Parkinson's disease (PD) associates with the progressive degeneration of nigro-striatal dopaminergic (DAergic) neurons in the substantia nigra pars compacta ( $\mathrm{SNpc}$ ), resulting in the development of motor symptoms such as resting tremor, muscle rigidity, and bradykinesia (Poewe and Mahlknecht 2009). Although the exact cause of idiopathic PD remains unknown, excessively high levels of localized iron concentrations within the brain has been deemed contributory to progressive PD (Sian-Hülsmann et al. 2011). Iron cytotoxicity ensues when iron exists in a labile state and elicits a cascade of cellular deleterious events, driven by participation in redox reactions i.e., the Haber-Weiss cycle (Halliwell and Gutteridge 1984). The pathogenic mechanism underlying iron-mediated cellular damage and eventual neuronal death seen in PD-affected brains likely involves excessive generation of intracellular free radicals [e.g., reactive oxygen species (ROS)], which eventually overwhelms the cell's antioxidant- or radical scavenging defense systems. This includes reducing levels of glutathione, a prominent brain anti-oxidant, resulting in oxidative damage to lipids, proteins, DNA, and mitochondria (Dixon and Stockwell 2014). SNpc DAergic neurons are particularly vulnerable to oxidative stress. Mechanisms underlying such selective vulnerability include nigral DAergic neurons' high iron levels and dopamine (DA) molecules' high rate of oxygen utilization (Sayre et al. 2005). The extensive SNpc DAergic damage seen in PD-affected brains contrasts with normal ageing, during which iron is more likely to be deposited in a different portion of the $\mathrm{SN}$, the pars reticulata part (Mastroberardino et al. 2009).

The ubiquitin proteasome system (UPS), a critical regulator of protein homeostasis in eukaryotic cells is deemed essential for maintaining iron homeostasis (Thompson and Bruick 2012). Under non-pathological conditions, the UPS keeps the cellular environment free of misfolded and defective proteins; however, several neurodegenerative diseases, including PD, is characterised by proteasomal dysfunction, resulting in accumulation of aggregation-prone proteins and thus aberrant iron homeostasis. In particular, $\alpha$-synuclein $(\alpha-\mathrm{SYN})$, an abundantly expressed 140-amino acid protein encoded by SNCA, involved in various cellular processes including DA release and -reuptake (Abeliovich et al. 2000; Braak et al. 2003), undergoes sequential aggregation during progressive $\mathrm{PD}$, to form so-called intracellular Lewy bodies (LBs) and Lewy neurites, which underlies PD pathology. Experimental evidence supports the notion that abnormal $\alpha-S Y N$ aggregates spread from brainstem to neocortex, propagating from cell-to-cell in a prion-like manner (Watts et al. 2013).

The realisation that protein fibrillisation comprises a fundamental pathological hallmark of PD-affected brains has resulted in increasing use of proteasome inhibitors for modeling PD both in vitro and in vivo, thereby serving as a test bed for novel therapeutic strategies. The microbial metabolite lactacystin induces a PD-like motor phenotype in rodents, concomitant with loss of DAergic cell bodies in the SNpc and DAergic terminals in the striatum, striatal DA depletion, as well as $\alpha-S Y N$ accumulation in remaining SN DAergic neurons (McNaught et al. 2002; Lorenc-Koci et al. 2011; Pienaar et al. 2015a, b; Savolainen et al. 2017). For instance, mice intracerebrally microinjected with lactacystin revealed increased iron deposition in the $\mathrm{SN}$, accompanied by nigral DAergic neurodegeneration (Zhu et al. 2010). Although the exact mechanism by which iron deposition associates with lactacystin neurotoxicity remains unknown, this study suggested that this may relate to abnormal regulation of iron-related 
proteins, including iron regulatory protein 2 (IRP2) and divalent metal transporter 1 (DMT1) (Zhu et al. 2010). Further evidence that iron plays an important role in PD neuropathology induced by UPS impairment stems from reports that pharmacological iron chelators such as desferoxamine (DFO) and 5-(4-(2-hydroxyethyl) piperazin-1-yl (methyl)-8-hydroxyquinoline (VK-28) prevented iron deposition and DAergic neurodegeneration in lactacystin-injected mice (Zhang et al. 2005; Zhu et al. 2007).

Hence, due to the putative interplay between lactacystininduced UPS impairment and iron misregulation, this toxin serves as a useful tool for exploring how an interplay between the iron-regulating and UPS pathways result in the DAergic neuronal degeneration and abnormal intracellular $\alpha$-SYNcontaining intracellular aggregates seen in PD. In addition, it serves as a translational cell model for assessing the diseasemodifying potential of chelators of labile iron. The therapeutic use of iron chelators for removing excessive amounts of iron and/or redox-silencing in PD patients is receiving considerable research and clinical attention (Ward et al. 2015). Previous work performed on rats showed that brain-permeable iron chelators can alleviate lactacystin-induced DAergic neuronal degeneration, restore proteasome activity and reduce the presence of ubiquitin-positive intracellular inclusions in the SN (Zhang et al. 2005; Zhu et al. 2007).

Here we provide physicochemical information on two novel 1,2-HOPO-based iron chelators, compounds C6 and C9 to quantify their chelating power towards $\mathrm{Fe}^{3+}$, the protonated species distribution and their complex formation with $\mathrm{Fe}^{3+}$ in relation to $\mathrm{pH}$. We previously studied $\mathrm{C} 6$ and $\mathrm{C} 9$ in SH-SY5Y human neuroblastoma cells exposed to 6-hydroxydopamine (6-OHDA) neurotoxic insult (Workman et al. 2015), which reproduce some features of PD-related neuropathology. These include increased ROS production, mitochondria functional inhibition and iron liberation from storage proteins such as ferritin (FT), resulting in DAergic neuronal death thereby impairing DA homeostasis (Alberio et al. 2012). The current study provides further characterization of the antioxidant, neuroprotective and neurorescuing properties as well as the ability by the novel iron chelators to reduce $\alpha-S Y N$ intracellular load in SH-SY5Y cells treated with lactacystin. We compared the compounds' effects to the clinically approved 3-hydroxy$4(1 \mathrm{H})$-pyridinone chelator, deferiprone (DFP), which was shown to improve PD patients' motor and non-motor symptoms (Moreau et al. 2018).

\section{Material and methods}

\section{Materials}

Distilled water was purified by passaging through a mixed bed of ion-exchanger (R3 type; Thermo Fisher Scientific,
Waltham, MA, USA) and activated carbon (the Oxygen Release Compound type; Thermo Fisher Scientific). Metal cation solutions were prepared from their perchlorate salts. Their concentrations were determined via colorimetric titrations with ethylenediaminetetraacetic acid (EDTA) solution (Titriplex III, Merck Millipore, Watford, UK), in accordance with standard procedures (Fish 1988; Skoog et al. 2000). Sodium hydroxide and perchloric acid were used to adjust $\mathrm{pH}$ during titrations. The ionic strength of all solutions was fixed at $0.1 \mathrm{M}$ using sodium perchlorate.

\section{Potentiometry}

The protonated forms of the ligands C6 and C9 $\left(10^{-3} \mathrm{M}\right)$ and the stability constants $(\log \beta)$ of their complexes with $\mathrm{Cu}^{2+}\left([\mathrm{L}] /\left[\mathrm{Cu}^{2+}\right] \approx 2.2, \mathrm{~L}=\mathrm{C} 6\right.$ or $\left.\mathrm{C} 9\right)$ were characterized by potentiometric titrations in water in accordance with a previously published procedure (Gillet et al. 2017) using an automatic titrator system (904 DMS Titrino, Metrohm Limited, Switzerland) with a combined glass electrode (6.0234.100; Long Life, Metrohm Limited, Switzerland) filled with $0.1 \mathrm{M}$ $\mathrm{NaCl}$. The $\mathrm{Fe}^{3+}$ complexes were already fully formed at $\mathrm{pH}$ 2 and could therefore not be studied via this technique.

The potentiometric data were refined with the Hyperquad 2008 program (Gans et al. 1996), which uses non-linear least-squares methods, considering the formation of metal hydroxide species. The titration of each system was repeated in triplicate. The distribution curves, as a function of the $\mathrm{pH}$ of the protonated forms of $\mathrm{C} 6, \mathrm{C} 9$ and their $\mathrm{Cu}^{2+}$ complexes, were calculated using the Hyperquad Simulation and Speciation (HySS 2009) software program (Alderighi et al. 1999).

\section{Spectrophotometry}

The protonation constant $(\log K)$ of a molecule is a key parameter that influences several of its drug-like properties, such as its lipophilicity, half-life, oral bioavailability, and the ability to cross cell membranes and also the blood-brain barrier. The $\log K$ values of the ligands $\mathrm{C} 6$ and $\mathrm{C} 9$ and their stability constants with $\mathrm{Cu}^{2+}$ and $\mathrm{Fe}^{3+}$ were determined by ultraviolet (UV)-visible spectrophotometric titrations versus $\mathrm{pH}$, by simultaneously recording $\mathrm{pH}$ and $\mathrm{UV}$-visible spectra. Between $\mathrm{p}[\mathrm{H}]=-0.5$ and $\mathrm{p}[\mathrm{H}]=2$ (brackets indicate that the $\mathrm{pH}$ value was calculated) the batch technique was used, following a previously published procedure (Gillet et al. 2017).

Direct titrations were carried out between $\mathrm{pH} 2$ and 12.5. For the protonation studies, an aliquot of $30 \mathrm{ml}$ of ligand C6 or C9 solution was introduced into a thermostat-jacketed cell $\left(25.0(2){ }^{\circ} \mathrm{C}\right)$. A known volume of perchloric acid solution was added to adjust the $\mathrm{pH}$ to 2 and a dynamic titration was carried out by adding known volumes of $\mathrm{NaOH}$ solution using a Metrohm 904 Titrino 
equipped with a Dosino 800 burette driven by the version 2.5 TiAmo software. The titrator was interfaced with an Agilent Cary 60 UV-visible spectrophotometer which automatically recorded a spectrum after an equilibration time of $2 \mathrm{~min}$, following each addition of base. The complexation studies of $\mathrm{C} 6$ and $\mathrm{C} 9$ with $\mathrm{Fe}^{3+}$ and $\mathrm{Cu}^{2+}$ were carried out in the same way, on L:M stoichiometric ratios $\left([\mathrm{L}] /\left[\mathrm{Fe}^{3+}\right]=3.2\right.$ and $\left.[\mathrm{L}] /\left[\mathrm{Cu}^{2+}\right]=2.2\right)$.

Competition experiments with EDTA in HEPES (4-(2-hydroxyethyl)-1-piperazineethanesulfonic acid) buffer (pH 7.4) were also carried out using the batch technique. Each batch sample contained an equivalent concentration of $\mathrm{FeL}_{3}$ complex $\left([\mathrm{L}] /\left[\mathrm{Fe}^{3+}\right]=3.2, \mathrm{~L}=\mathrm{C} 6\right.$ or $\left.\mathrm{C} 9\right)$ and increasing amounts of EDTA $\left(0<[\right.$ EDTA $\left.] /\left[\mathrm{Fe}^{3+}\right]<1\right)$. The sample was left to equilibrate overnight before a UV-visible spectrum and the same was recorded. All the spectrophotometric data were fitted with HypSpec software (https://www.hyper quad.co.uk) (Gans et al. 1996), for calculating the protonation constants of the ligands, the stability constants $(\log \beta)$ of the formed species and the coordination model of the studied systems.

\section{Distribution coefficients}

The lipophilicity of the ligands C6 and C9, along with their corresponding $\mathrm{Fe}^{3+}$ complexes, were determined by calculating their respective distribution coefficient $\left(\log D_{7.4}\right)$ values using the Shake Flask method, by referring to the published method of Ma and colleagues (Ma et al. 2012). The method rests on the principle that the solute's distribution is determined as a ratio of concentrations of the test compound in a solution mixture, consisting of two immiscible phases, namely $n$-octanol and aqueous HEPES buffer (pH 7.4).

\section{2,2-Diphenyl-1-picrylhydrazyl assay}

The 2,2-diphenyl-1-picrylhydrazyl (DPPH) assay was performed with $\mathrm{C} 6$ and $\mathrm{C} 9$, in accordance with previously published methods (Blois 1958). For this, $50 \mu \mathrm{l}$ of different concentrations of C6, C9 and DFP (0.01 to $0.1 \mathrm{mg} / \mathrm{ml}$ in methanol) was dissolved in $2 \mathrm{ml}$ of DPPH methanolic solution (the concentration was adapted to achieve an absorbance of $\sim 1$ ). The samples were shaken vigorously and were allowed to stand until the reaction reached steady-state. The absorbance of the samples was then measured at $515 \mathrm{~nm}$ using a UV-visible absorption spectrophotometer (UV-2401 PC; Shimadzu Corporation, Kyoto, Japan). Scavenging of DPPH free radicals was calculated as: DPPH scavenging activity $(\%)=[(\mathrm{Ac}-\mathrm{At}) / \mathrm{Ac}] \times 100$ where, $\mathrm{Ac}$ is the absorbance of the control tube (containing all reagents except the test compound), while At is the absorbance of the test tube.

\section{Deoxyribose degradation assay}

To investigate the origin of the antioxidant properties of the ligands (direct $\mathrm{OH}$ scavenging activity or indirect inhibition of the Fenton reaction through Fe chelation), we applied the deoxyribose degradation assay (DDA) with $\mathrm{FeCl}_{3}$ or FeEDTA as the $\mathrm{Fe}^{3+}$ source, as previously described (Chaves et al. 2012). Briefly, a mixture of ascorbic acid, $\mathrm{H}_{2} \mathrm{O}_{2}$ and FeEDTA (or $\mathrm{FeCl}_{3}$ ) complex generated hydroxyl radicals via the Fenton reaction. These radicals subsequently react with deoxyribose to generate malondialdehyde, which in turn reacts with thiobarbituric acid (TBA) to form a pink chromogen. Each assay consisted of $20 \mathrm{mM} \mathrm{KH} \mathrm{PO}_{4} /$ $\mathrm{K}_{2} \mathrm{HPO}_{4}$ buffer (pH 7.4), $2.8 \mathrm{mM}$ deoxyribose, $0.1 \mathrm{mM}$ $\mathrm{FeCl}_{3}, 0.1 \mathrm{mM}$ EDTA, different concentrations of the ligand (0.6-3.0 mM), $0.2 \mathrm{mM} \mathrm{H}_{2} \mathrm{O}_{2}$ and $0.1 \mathrm{mM}$ ascorbic acid, in a final volume of $1.0 \mathrm{ml}$. Solutions of $\mathrm{FeCl}_{3}-\mathrm{EDTA}, \mathrm{H}_{2} \mathrm{O}_{2}$ and TBA, were made up immediately before use, with ascorbic acid that was added to initiate the reaction. In the presence of $\mathrm{OH}$, deoxyribose is degraded to a product which, when heated with TBA at acidic $\mathrm{pH}$ forms a pink chromogen. After incubating the solutions for $1 \mathrm{~h}$ at $37^{\circ} \mathrm{C}$, the color reaction was developed by adding $1 \mathrm{ml}$ of $2.8 \%(\mathrm{w} / \mathrm{v})$ trichloroacetic acid and $1 \mathrm{ml}$ of $1 \%(\mathrm{w} / \mathrm{v})$ TBA to $0.05 \mathrm{M}$ $\mathrm{NaOH}$, followed by heating the reaction mixture for $30 \mathrm{~min}$ at $100{ }^{\circ} \mathrm{C}$. The solutions were cooled, after which absorbance was measured spectrophotometrically at a wavelength of $532 \mathrm{~nm}\left(\lambda_{\max }\right)$. Controls containing no deoxyribose in the reaction mixture were included for all ligand concentrations.

\section{Cell culture, drug and neurotoxin treatment paradigm}

Undifferentiated, adherent human neuroblastoma SHSY5Y cells (cat \#: ECACC 94030304) were obtained from the European Collection of Authenticated Cell Cultures (ECACC, Salisbury, UK). Cells were maintained in complete growth medium (Dulbecco's Modified Eagle's medium (DMEM) with Ham's F12, 10\% foetal bovine serum (FBS; Sigma-Aldrich, St. Louis, MO, USA), 10,000 units/ ml penicillin (Life Technologies, Carlsbad, CA, USA) and $10,000 \mu \mathrm{g} / \mathrm{ml}$ streptomycin (Life Technologies) at $37{ }^{\circ} \mathrm{C}$ in 5\% $\mathrm{CO}_{2}$. Cells were plated in 96-well plates for $48 \mathrm{~h}$ at 4000 cells $/ 100 \mu$ DMEM with $10 \%$ FBS for determining cell viability (determined by hemocytometer cell count) with a similar density used for Western immunoblotting, whilst 20,000 cells $/ 100 \mu \mathrm{l}$ DMEM with $10 \%$ FBS was plated for measuring ROS levels. For assessing the ability of C6 and C9 to provide cytoprotection against proteasome inhibition via lactacystin, either C6, C9 or DFP, all at a dose of $100 \mu \mathrm{M}$ (dissolved in media), was added to the cell cultures for $24 \mathrm{~h}$, followed by addition of the irreversible proteasome inhibitor, lactacystin (5 $\mu \mathrm{M}$, Enzo Life Sciences, UK) for a 
further $24 \mathrm{~h}$. We also determined the cell death rescue effects of each of the compounds of interest compared to DFP, by treating the cell cultures for $24 \mathrm{~h}$ with lactacystin, followed by $100 \mu \mathrm{M}$ of C6, C9 or DFP. Stock solutions of lactacystin were prepared in fresh medium containing $100 \%$ dimethyl sulfoxide (DMSO), which was diluted in fresh medium, to a final DMSO concentration of $0.05 \%$. Control conditions were included for all biochemical assays, i.e., for the cytoprotection assay, the control cells were incubated with the compound of interest for $24 \mathrm{~h}$, followed by treatment with the toxin's vehicle $(0.05 \%$ DMSO, dissolved in media) for another $24 \mathrm{~h}$, whilst for the rescue assay, the compoundtoxin vehicle treatment protocols were reversed.

\section{Inductively-coupled-plasma mass spectroscopy}

Iron, copper and zinc levels were measured via inductivelycoupled-plasma mass spectroscopy (ICP-MS), similar to a previously published protocol (Duce et al. 2010). In brief, $150 \mu \mathrm{g}$ of total protein was lyophilized before resuspension in $100 \mu \mathrm{l}$ Aristar-grade nitric acid (69\% v/v), overnight at RT. Samples were then heated at $90{ }^{\circ} \mathrm{C}$ for $1 \mathrm{~h}$, before adding an equivalent volume of $30 \%$ hydrogen peroxide $\left(\mathrm{H}_{2} \mathrm{O}_{2}\right.$; Merck Millipore). Samples were then incubated for $15 \mathrm{~min}$ at RT before heating for $30 \mathrm{~min}$ at $70{ }^{\circ} \mathrm{C}$. To evaluate metal content against calibration standards (IMS-102; Ultra Scientific, North Kingston, RI, USA) samples were diluted in double-distilled water until within quantifiable parameters using a NexION 350X ICP-MS (PerkinElmer, Waltham, MA, USA). Each sample was measured in triplicate and normalized to its total protein concentration.

\section{Cell viability assay}

Cell viability was assessed via a 3-(4,5-dimethylthiazol2-yl)-5-(3-carboxymethoxyphenyl)-2-(4-sulfophenyl)2H-tetrazolium (MTS) assay, which utilizes the ability of mitochondria to reduce a substrate (MTS) into a soluble formazan product. For the assay, the CellTiter 96 $\mathrm{AQ}_{\text {ueous }}$ One Solution cell proliferation colorimetric assay kit was used, in accordance with the manufacturer's instructions (Promega, Madison, WI, USA). The MTS assay was performed using 96-well plates containing the treated cells. Following the treatment paradigms, $20 \mu \mathrm{MTS}$ reagent was added to each well, and the plates incubated at $37^{\circ} \mathrm{C}$ for $3 \mathrm{~h}$. The absorbance of the solution was read at $490 \mathrm{~nm}$ using a FLUOstar Omega spectrophotometer (BMG LabTech, Germany). Experiments were performed in triplicate. Results were expressed as a percentage of control. The MTS assayderived data were validated by means of traditional trypan blue dye exclusion. For this, an aliquot of cell suspension in PBS was mixed with an equal volume of trypan blue solution $(0.4 \%$ in PBS). In total, $10 \mu \mathrm{l}$ of cells were added to a
Neubauer haemocytometer chamber and the average number of cells was counted by an observer blind to treatment protocol. Cell death was expressed as percentage trypan blue positive cells per total population of stained and unstained cells.

\section{Intracellular and extracellular ROS level measurements}

Production of intracellular ROS (iROS) and also extracellular ROS (eROS) was determined using the substrate dihydrorhodamine (DHR)-123 (Sigma-Aldrich), a nonfluorescent laser dye that becomes oxidized by ROS to the fluorescent Rhodamine 123 (Kirchner et al. 2012). For measuring iROS levels using the DHR-123 assay, we followed published guidelines (Wang et al. 2016; Das et al. 2015), as well as the manufacturer's guidelines, available online (https://www.sigmaaldrich.com/catalog/product/sial/d1054). Briefly, SH-SY5Y cells (20,000 cells/100 $\mu$ LMEM for each well) were plated and cultured in 96-well plates for $48 \mathrm{~h}$. Lactacystin ( $5 \mu \mathrm{M}$, Enzo Life Sciences) was then applied for $24 \mathrm{~h}$, followed by treatment with either C6, C9 or DFP (all at $100 \mu \mathrm{M}$, dissolved in medium) for a further $24 \mathrm{~h}$, without removal of the lactacystin solution. After the $48 \mathrm{~h}$ period of incubating the cells with the toxin and drugs, using typical incubator conditions $\left(5 \% \mathrm{CO}_{2}, 95 \%\right.$ air at $\left.37{ }^{\circ} \mathrm{C}\right)$, the medium was discarded, and the cells were incubated in the dark with $100 \mu$ l of $10 \mu \mathrm{M}$ DHR-123 solution and supplement-free growth medium, at typical incubator conditions for $30 \mathrm{~min}$, similar to the DHR-123 incubation period proposed in several published protocols (e.g., Das et al. 2015; Meng et al. 2016; Wang et al. 2016). Subsequently, the medium was removed and the cells were washed with PBS $(\times 3)$ before immediate analysis of the fluorescence intensity of each well using a microplate reader (FLUOstar Omega), with an excitation filter of $485 \mathrm{~nm}$ and an emission filter of $520 \mathrm{~nm}$.

For determining eROS levels, the procedure was repeated until after the cells had been incubated with DHR-123 solution, for the same period of time and dose as was used for determining iROS. The culture media was then transferred (without detaching the adherent cells) to a fresh 96-well microplate for measuring extracellular fluorescence intensity, as described above.

\section{Cell lysis, protein extraction and protein estimation}

For preparing whole cell lysates, cells were washed with ice-cold phosphate-buffered saline (PBS), harvested and then lysed in radio-immunoprecipitation assay (RIPA) buffer $(50 \mathrm{mM}$ Tris pH 7.4, $150 \mathrm{mM} \mathrm{NaCl}, 1 \%$ sodium deoxycholate, $1 \%$ Triton $\mathrm{X}-100,0.1 \%$ sodium dodecyl sulfate; Sigma-Aldrich), also containing a protease inhibitor 
cocktail consisting of 4-(2-aminoethyl) benzenesulfonyl fluoride $(2 \mathrm{mM})$, aprotinin $(0.3 \mu \mathrm{M})$, bestatin $(116 \mu \mathrm{M})$, E-64 $(14 \mu \mathrm{M})$, leupeptin $(1 \mu \mathrm{M})$ and EDTA $(1 \mathrm{mM})$. The suspension was homogenized in a fresh Eppendorf tube by shaking for $15 \mathrm{~min}$ on ice. Samples were clarified to remove denatured nucleic acid by centrifugation at $14,000 \times g$ for $15 \mathrm{~min}$ at $4{ }^{\circ} \mathrm{C}$. The protein containing the supernatant was then transferred to new tubes before total protein concentration was determined in each sample via a Bradford assay (Bradford Reagent, Sigma-Aldrich).

\section{Western blots}

SH-SY5Y cells (4000 cells/100 $\mu$ l DMEM with $10 \%$ FBS) were cultured in 96-well plates for $48 \mathrm{~h}$ before lactacystin ( $5 \mu \mathrm{M}$, Enzo Life Sciences) treatment for $24 \mathrm{~h}$, followed by the specific compound treatment protocols for a further $24 \mathrm{~h}$ (resulting in cells being exposed to lactacystin for $48 \mathrm{~h}$ ). To prepare whole cell lysates, the cells were washed in ice-cold PBS, harvested and then lysed with RIPA buffer containing 4-2-aminoethyl benzenesulfonyl fluoride $(2 \mathrm{mM})$, aprotinin $(0.3 \mu \mathrm{M})$, bestatin $(116 \mu \mathrm{M})$, E-64 $(14 \mu \mathrm{M})$, leupeptin $(1 \mu \mathrm{M})$ and EDTA $(1 \mathrm{mM})$. The lysates were centrifuged at 13,000 rotations per minute for $15 \mathrm{~min}$ at $4{ }^{\circ} \mathrm{C}$, with the supernatant used for analysis. Protein concentrations were determined using the Bradford protein assay (Bio-Rad Laboratories). Prior to immunoblotting, protein extracts were separated on a $10 \%$ sodium dodecyl sulphate polyacrylamide gel electrophoresis (SDS-PAGE) and then transferred to Immobilon-P polyvinylidene difluoride (PVDF) membranes (Bio-Rad Laboratories) using an electrophoretic transfer cell (Mini Trans-Blot ${ }^{\circledR}$, BioRad Laboratories) and by applying constant current at $200 \mathrm{~mA}$ for $1.5 \mathrm{~h}$. The blots were blocked with $5 \% \mathrm{w} / \mathrm{v}$ dried milk in PBS for 90 min before incubating for $4 \mathrm{~h}$ in a solution containing rabbit anti- $\alpha-S Y N$ primary antibody (1:1,000 dilution; Cell Signalling Technology, UK) on a shaker at $4{ }^{\circ} \mathrm{C}$. After incubation with horseradish peroxidase (HRP)-conjugated secondary antibody (polyclonal goat anti-rabbit, 1:3,000 dilution, Abcam, Cambridge, $\mathrm{UK}$ ) for $2 \mathrm{~h}$ at room temperature (RT), immunoreactive proteins were visualized by enhanced chemiluminescence detection kit (Pierce ${ }^{\mathrm{TM}}$ ECL plus Western Blotting Substrate, Thermo Fisher Scientific). The light-emitting bands were detected with X-ray film. An anti-GAPDH (glyceraldehyde-3-phosphate dehydrogenase) antibody (polyclonal rabbit; 1:1,000 dilution, Chemicon International, Inc., Billerica, MA, USA) was used as a control. The band intensities were quantified by densitometric analysis using ImageJ software (v1.45 software, Wayne Rasband, National Institute of Health, USA).

\section{Nuclear magnetic resonance spectroscopy}

The potential trapping of the reactive lactone formed by lactacystin (clasto-lactacystin $\beta$-lactone) by C6 was studied via ${ }^{1} \mathrm{H}$ Nuclear Magnetic Resonance (NMR) spectroscopy and mass spectrometry (MS) in two deuterated solvent systems, namely DMSO- $d_{6}$ and $10 \%$ DMSO- $d_{6}$ in $\mathrm{D}_{2} \mathrm{O}$. Lactacystin $\left(200 \mu \mathrm{g}, 5.313 \times 10^{-7} \mathrm{~mol}\right)$ was dissolved in $0.2 \mathrm{ml}$ DMSO$d_{6}$, with $0.1 \mathrm{ml}$ of this solution that was removed and diluted to a total volume of $0.5 \mathrm{ml}$ with DMSO- $d_{6}$. This solution was placed in an NMR tube and the ${ }^{1} \mathrm{H}$ NMR spectrum recorded on a JEOL ECS400FT Delta spectrometer $(399.78 \mathrm{MHz}$ for ${ }^{1} \mathrm{H}$ ) to obtain a reference (in DMSO- $d_{6}$ ). The remaining $0.1 \mathrm{ml}$ of lactacystin solution was diluted to a volume of $1 \mathrm{ml}$ with $\mathrm{D}_{2} \mathrm{O}$; the spectrum was recorded similarly (in $10 \%$ DMSO- $d_{6}$ in $\left.\mathrm{D}_{2} \mathrm{O}\right)$. Reference NMR spectra of C6 $(1.328 \mu \mathrm{M})$ in each of these solvent systems were obtained. For each solvent system, $0.2 \mathrm{ml}$ ( 1 molar equivalent) of C6 stock solution was added to the NMR tube containing lactacystin. The NMR tube was then inverted to mix several times, before the ${ }^{1} \mathrm{H}$ NMR spectrum was recorded. A total of three additions ( 3 molar equivalents) of $\mathrm{C} 6$ stock solution were added to each NMR tube and the NMR spectra were recorded each time. PBS $(0.2 \mathrm{ml}, \mathrm{pH}=7.4)$ was then added to each NMR tube to raise the $\mathrm{pH}$ from 7.0 to 7.4 and the NMR spectra were re-recorded. Aliquots from each NMR tube were then analysed by MS using electrospray ionization (ThermoFinnigan LCQ Advantage Max mass spectrometer, ThermoFinnigan Corporation, San Jose, CA, USA).

\section{Statistical analyses}

Statistical significance was calculated by means of a oneway ANOVA followed by a Dunnett's post-hoc test to assess for differences between the groups. Statistical tests were performed using GraphPad Prism version 7 (GraphPad Software, Inc., CA, USA). A $p$ value $\leq 0.05$ was considered statistically significant. Values are expressed as the mean \pm standard deviation (SD) of triplicate observations.

\section{Results}

\section{Physicochemical characterization}

A detailed physicochemical study was carried out in aqueous solution on ligands $\mathrm{C} 6$ and $\mathrm{C} 9$ to assess their coordination model, affinity for $\mathrm{Fe}^{3+}$ and $\mathrm{Cu}^{2+}$ and selectivity. The lipophilicity and antioxidant ability of the ligands and their $\mathrm{Fe}^{3+}$ complexes were also evaluated via $\log \mathrm{D}_{7,4}$, as well as DPPH and DDA assay determination, respectively. 


\section{Protonation properties versus $\mathrm{pH}$}

The protonation properties of ligands C6 and C9 were studied through both potentiometric titrations and UV-Vis absorption spectrophotometric titrations versus pH (Fig. 1a). The acido-basic properties of ligands C6 (Fig. 1b) and C9 (Fig. 1c, d) as well as their metal complexes were also studied in strongly acidic conditions between $\mathrm{p}[\mathrm{H}]-0.5$ and 2 by means of spectrophotometric titrations versus $\mathrm{p}[\mathrm{H}]$ (brackets indicate that the $\mathrm{pH}$ value was calculated). As such low $\mathrm{p}[\mathrm{H}]$ cannot be measured with an electrode, the batch titration technique was used and the $\mathrm{p}[\mathrm{H}]$ of the solutions was fixed by adding known volumes of standardized $\mathrm{HClO}_{4}$ (see material and methods section for details). The ionic strength was not fixed below $\mathrm{p}[\mathrm{H}] 1$ in the batch titrations and no decomposition of the ligands was observed, even under
Fig. 1 a Poten-

tiometric titrations of $\mathrm{C} 6$

$\left([\mathrm{C} 6]=1.01 \times 10^{-3} \mathrm{M}\right)$ and $\mathrm{C} 9$

([C9] $=9.96 \times 10^{-4}$ M). b Spectrophotometric titrations versus $\mathrm{pH}$ of $\mathrm{C} 6\left([\mathrm{C} 6]=1.54 \times 10^{-4} \mathrm{M}\right.$, batch titration $-0.5<\mathrm{pH}<2$ and direct titration $2<\mathrm{pH}<11.38$ ).

Spectrophotometric titration versus $\mathrm{pH}$ of $\mathrm{C} 9$ between c $-0.5 \leq \mathrm{pH} \leq 2$ (batch titration, $[\mathrm{C} 9]=3.0 \times 10^{-4} \mathrm{M}$ and d $2.02 \leq \mathrm{pH} \leq 13.02$ (direct titration, [C9] $\left.=1.48 \times 10^{-4} \mathrm{M}\right)$. e Electronic spectra and

f distribution curves ([C6] $=1.54 \times 10^{-4} \mathrm{M}$ ) of the protonated species of ligand C6. g Electronic spectra and $\mathbf{h}$ distribution curves of the protonated species of $\mathrm{C} 9$ $\left([\mathrm{C} 9]=3.0 \times 10^{-4} \mathrm{M}\right)$. Solvent: $\mathrm{H}_{2} \mathrm{O}, I=0.1 \mathrm{M}\left(\mathrm{NaClO}_{4}\right)$, $T=25.0{ }^{\circ} \mathrm{C}$ for all measurements (a)

$$
L H_{n-1}+H \leftrightarrow L H_{n}
$$

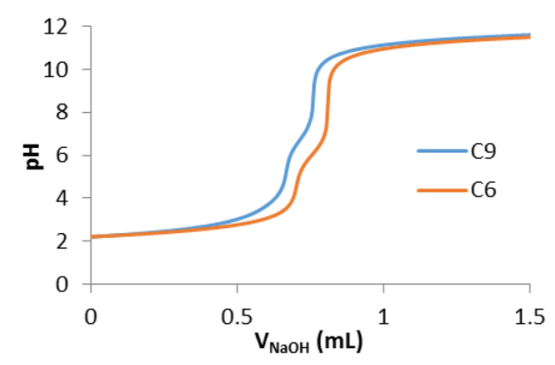

(c)

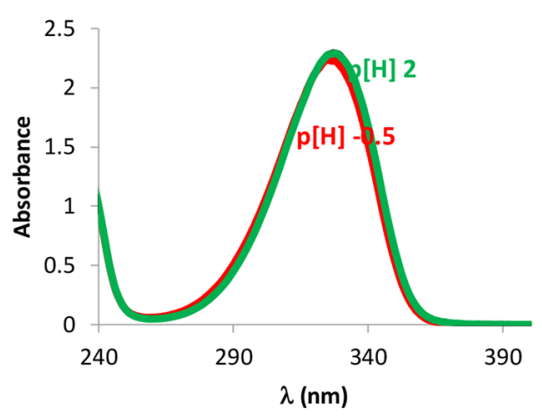

(e)

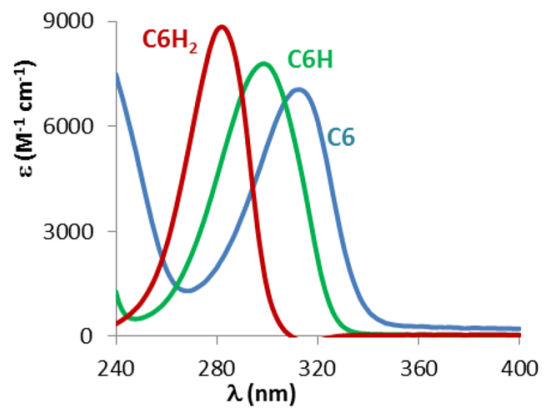

(g)

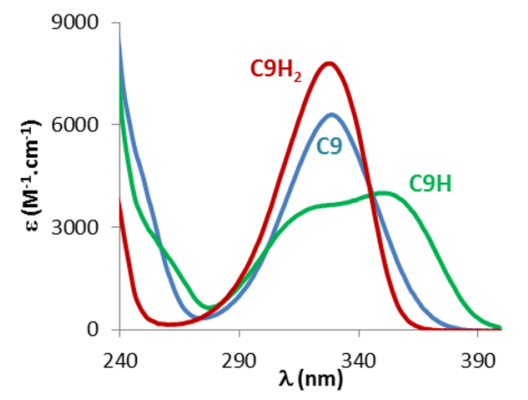

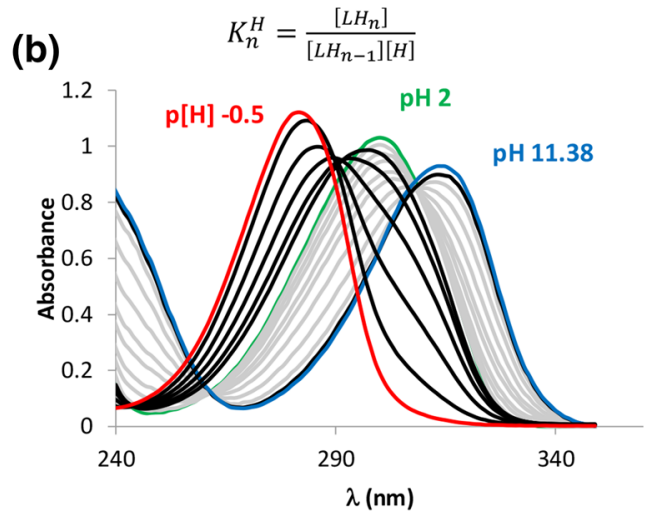

(d)

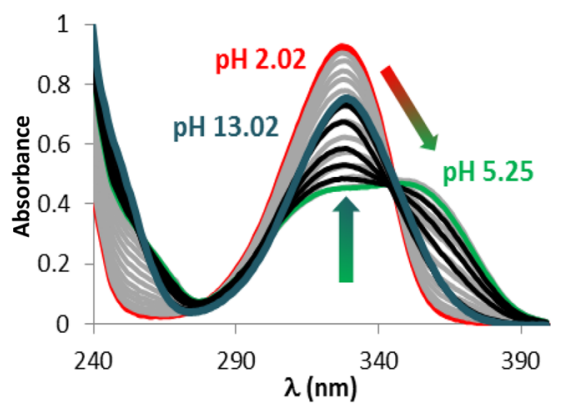

(f)

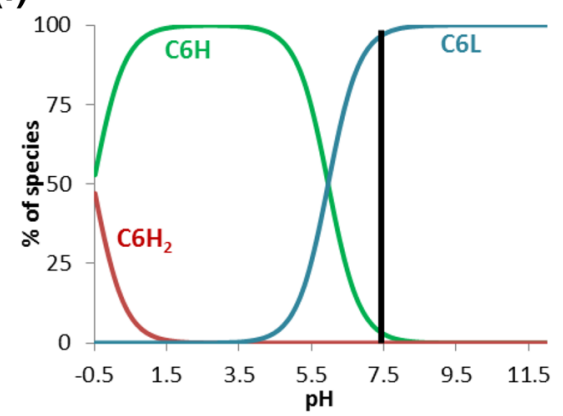

(h)

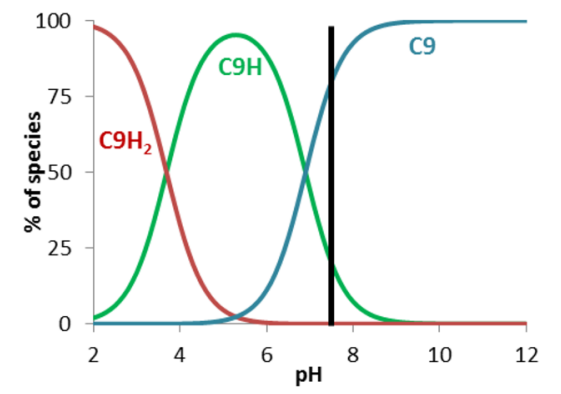


highly acidic conditions. For C6, a $\log K_{2}{ }^{\mathrm{H}}$ was determined from the spectral variations in the batch titration between $\mathrm{p}[\mathrm{H}]-0.5$ and 2 (Fig. 1b) and may be attributed to the protonation of the 2-oxo group, similarly to 1,2-HOPO (Gardner and Katritzky 1957). Similar titration of C9 showed no evidence of protonation in this $\mathrm{p}[\mathrm{H}]$ range (Fig. 1c), suggesting that the additional intra-molecular hydrogen bond between the carboxylic acid and the 2-oxo group precludes protonation of this group.

The average protonation constant $(\log K)$ values $( \pm \mathrm{SD})$ are shown in Table 1; those of DFP and 1,2-HOPO are given for comparison. $\log K_{1}{ }^{\mathrm{H}}$ was attributed to the $\mathrm{N}-\mathrm{OH}$ proton for both ligands and $\log K_{2}{ }^{\mathrm{H}}$ corresponds to the carboxylic acid proton in the case of $\mathrm{C} 9$. Measurement of protonation constants of $\mathrm{C} 6$ and $\mathrm{C} 9$ allowed us to calculate the electronic spectra of their protonated species (C6, Fig. 1e; C9, Fig. $1 \mathrm{~g}$ ), as well as their distribution diagrams (C6, Fig. 1f; C9, Fig. 1h). These showed that under physiological $\mathrm{pH}$ conditions ( $\mathrm{pH} 7.4$ ), C6 exists primarily (96\%) in its totally deprotonated form $\left(\mathrm{C}^{-}\right)$, in accordance with a $\log D_{7.4}$ value of $-1.71(7)$, while under similar conditions, DFP is primarily in its neutral form and has a $\log D_{7,4}$ value of $-0.77(2)$ (Table 1). At this $\mathrm{pH}, \mathrm{C} 9$ existed as a mix of its totally deprotonated form $\left(\mathrm{C}^{2-}, 80 \%\right)$ and monoprotonated form $\left(\mathrm{C}^{-} \mathrm{H}^{-}, 20 \%\right)$ with the hydroxamic acid group being protonated. These low protonation constants suggest that C6 and $\mathrm{C} 9$ would have a poor ability to cross cell membranes via passive diffusion.

However, despite their relatively low protonation constants, both $\mathrm{C} 6$ and $\mathrm{C} 9$ clearly reduced intracellular $\mathrm{Fe}^{3+}$ in the SH-SY5Y cells, as was revealed by our results that labile iron was reduced which resulted in downstream beneficial effects, as discussed later.

\section{Complex formation with $\mathrm{Fe}^{3+}$ and $\mathrm{Cu}^{2+}$ versus $\mathrm{pH}$}

Similar to the protonation study, spectrophotometric batch $(-0.5<\mathrm{p}[\mathrm{H}]<2)$ and direct $(2<\mathrm{pH}<12)$ titrations were then carried out on the $\mathrm{Fe}^{3+}$ complexes of ligands $\mathrm{C} 6$ (Fig. 2a, b) and C9 (Fig. 2c, d). The titrations showed the appearance of a ligand to metal charge transfer band (LMCT) centered around $480 \mathrm{~nm}$ for both ligands, characteristic of

Table 1 Successive protonation constants $(\log K)$ and partition coefficients $\left(\log D_{7.4}\right)$ of C6, C9, DFP and 1,2-HOPO

\begin{tabular}{lllcl}
\hline & C6 & C9 & DFP [56] & 1,2-HOPO [57] \\
\hline $\log K_{1}{ }^{\mathrm{H}}$ & $6.02(5)$ & $6.9(1)$ & 9.77 & $5.81(2)$ \\
$\log K_{2}{ }^{\mathrm{H}}$ & $-0.53(6)$ & $3.70(6)$ & 3.68 & $-0.9(3)$ \\
$\log D_{7,4}$ & $-1.71(7)$ & $/$ & $-0.77(2)$ & $/$ \\
\hline
\end{tabular}

Solvent: $\mathrm{H}_{2} \mathrm{O}, I=0.1 \mathrm{M}\left(\mathrm{NaClO}_{4}\right), T=25.0{ }^{\circ} \mathrm{C}$. The numbers given in parentheses correspond to the $\mathrm{SD}$ expressed to the last significant figure the complexation of $\mathrm{Fe}^{3+}$. This band undergoes a hyper- and hypsochromic shift to $410 \mathrm{~nm}$ as $\mathrm{pH}$ increases, sign of the successive coordination of one, two, and three bidentate ligands to the $\mathrm{Fe}^{3+}$ cation to achieve a hexacoordinate complex. When the $\mathrm{pH}$ continues to increase, a decrease of the charge transfer band was observed suggesting the substitution of ligands in the $\mathrm{Fe}^{3+}$ coordination sphere by hydroxide anions until the total release of $\mathrm{Fe}^{3+}$ and its precipitation as $\mathrm{Fe}(\mathrm{OH})_{3}$, as suggested by the total loss of the LMCT band and a general increase in noise and baseline in the titration of the complexes above pH 9.8 (Fig. 2b, d).

For both ligands, the presence of a hydroxylated complex, $\mathrm{FeL}_{2}(\mathrm{OH})_{2}(\mathrm{~L}=\mathrm{C} 6, \mathrm{C} 9)$, was observed before precipitation occurred. For ligand $\mathrm{C}$, that exhibited a non-coordinating carboxylic acid function, the additional formation of the protonated $\mathrm{Fe}(\mathrm{C} 9) \mathrm{H}$ species at a very acidic $\mathrm{pH}$ was also observed. The overall stability constants $(\log \beta)$ of the observed species are shown in Table 2, which also shows that the pFe values of both $\mathrm{C} 6$ and $\mathrm{C} 9$ are very similar, and around one order of magnitude lower than that of DFP.

To chelate labile $\mathrm{Fe}^{3+}$ and prevent oxidative damage, a therapeutic iron chelator must be able to form a reasonably stable $\mathrm{FeL}_{3}$ complex ( $\mathrm{L}=$ chelator) in which the inner coordination sphere of $\mathrm{Fe}^{3+}$ is fully saturated. However, the stability of the complex need not be so high as to result in total removal of $\mathrm{Fe}^{3+}$ from either the cell or from $\mathrm{Fe}^{3+}$-saturated transferrin. Determination of the stability constants of the C6 (Fig. 2e) and C9 (Fig. 2g) Fe ${ }^{3+}$ complexes allowed us to calculate the electronic spectra of their protonated species and compile their respective distribution diagrams (C6, Fig. 2f; C9, Fig. 2h), to show the major complex species present at physiological $\mathrm{pH}$.

Competition experiments were carried out with EDTA in HEPES buffer at pH 7.4 to verify our complexation model and confirm the $\mathrm{FeL}_{3}$ stability constants of C6 (Fig. 3a) and C9 (Fig. 3b), where $\mathrm{FeL}_{3}$ should be the only species present ( $\mathrm{L}=\mathrm{C} 6$ or $\mathrm{C} 9$ ). The fitting of the data confirmed the presence of a single $\mathrm{FeL}_{3}$ species for both ligands. The conditional stability constants of the $\mathrm{FeL}_{3}$ complexes were determined and converted to overall stability constants (Ringbom 1963) which were found to be in good agreement with those obtained from the spectrophotometric titrations versus $\mathrm{pH}$ (Table 2).

Since $\mathrm{Cu}^{2+}$ is also redox-active and implicated in PD pathogenesis, we also studied the $\mathrm{Cu}^{2+}$ binding affinity of $\mathrm{C} 6$ and $\mathrm{C} 9$. In the case of $\mathrm{Cu}^{2+}$ complexation, spectrophotometric titrations versus $\mathrm{pH}$ showed the successive formation of $\mathrm{CuL}$ and $\mathrm{CuL}_{2}$ complexes for both $\mathrm{C} 6$ and C9 ligands (Fig. 4a-d), followed by decomplexation and precipitation of $\mathrm{Cu}(\mathrm{OH})_{2}$ above $\mathrm{pH} 9$ (Fig. 4e, f). Similar to $\mathrm{Fe}^{3+}$ complexation, ligand $\mathrm{C} 9$ showed the additional formation of the protonated $\mathrm{Cu}(\mathrm{C} 9) \mathrm{H}$ species. The affinity of $\mathrm{C} 6$ and $\mathrm{C} 9$ (Table 2) for $\mathrm{Cu}^{2+}$ was ca. 7 orders of 
Fig. 2 Spectrophotometric titration versus $\mathrm{pH}$ of $\mathrm{Fe}^{3+}$ complexes of $\mathrm{C} 6$ between $\mathbf{a}-0.75 \leq \mathrm{pH} \leq 2$ (batch titration, [C6] $\left.=3.0 \times 10^{-4} \mathrm{M}\right)$ and b $2.02 \leq \mathrm{pH} \leq 11.59$ (direct titration, [C6] $=3.0 \times 10^{-4} \mathrm{M}$ ) $[\mathrm{C} 6] /\left[\mathrm{Fe}^{3+}\right]=3.2$. Spectrophotometric titration versus $\mathrm{pH}$ of $\mathrm{Fe}^{3+}$ complexes of ligand C9 between $\mathbf{c}-0.25<\mathrm{pH}<2$ (batch titration) and $\mathbf{d}$ $1.99<\mathrm{pH}<12.02$ (direct titration) $[\mathrm{C} 9]=3.0 \times 10^{-4} \mathrm{M}$, $[\mathrm{C} 9] /\left[\mathrm{Fe}^{3+}\right]=3.2$. e Electronic spectra and $\mathbf{f}$ distribution curves ([C6] $\left.=3.0 \times 10^{-4} \mathrm{M}\right)$ of the $\mathrm{Fe}^{3+}$ complexes of C6. $\mathrm{g}$ Electronic spectra and $\mathbf{h}$ distribution curves $\left([\mathrm{C} 9]=3.0 \times 10^{-4} \mathrm{M}\right.$, $[\mathrm{C} 9] /[\mathrm{Fe}(\mathrm{III})]=3.2)$ of the $\mathrm{Fe}^{3+}$ complexes of C9. Solvent: $\mathrm{H}_{2} \mathrm{O}$, $I=0.1 \mathrm{M}\left(\mathrm{NaClO}_{4}\right), T=25.0^{\circ} \mathrm{C}$ for all measurements (a)

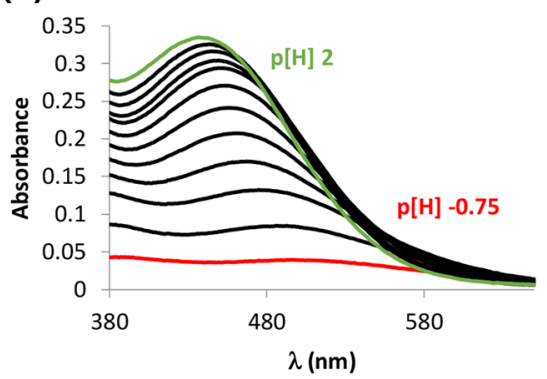

(c)

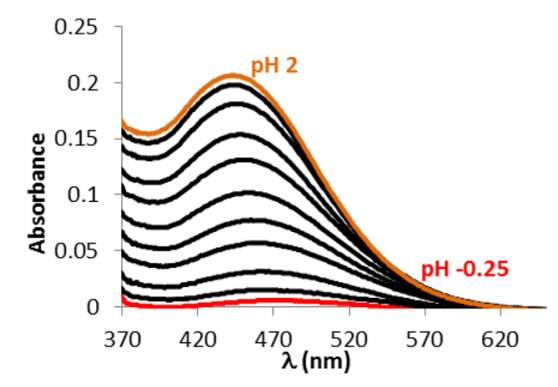

(e)

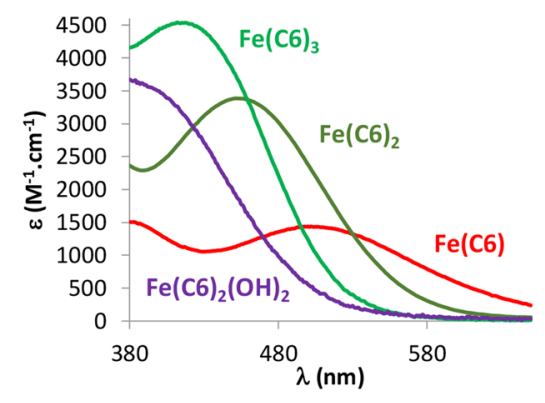

(g)

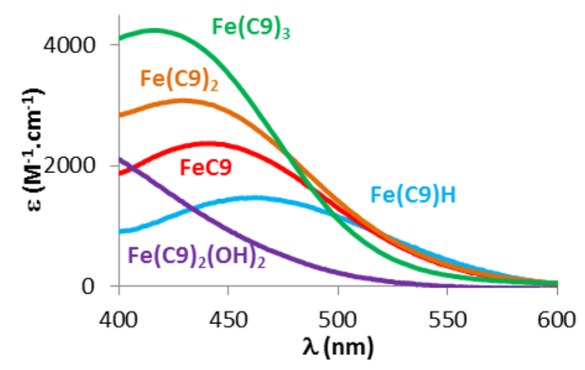

(b)

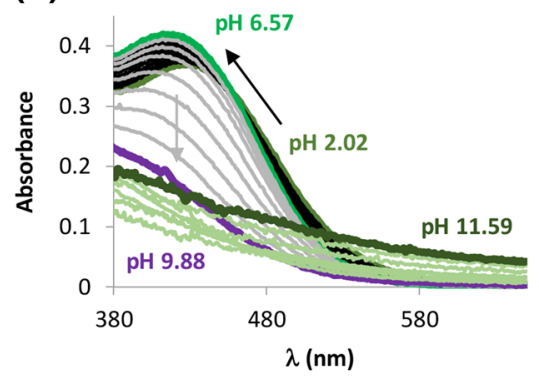

(d)

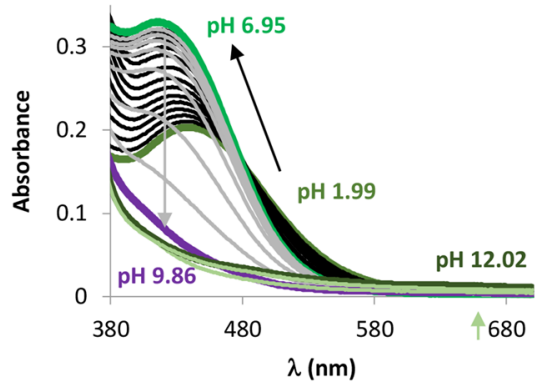

(f)

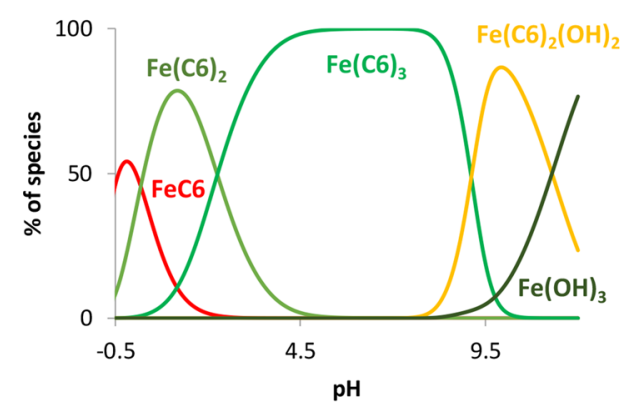

(h)

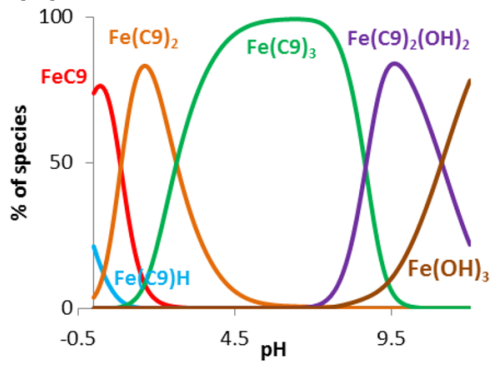

magnitude lower than their affinity for $\mathrm{Fe}^{3+}$, suggesting that both compounds have excellent selectivity for $\mathrm{Fe}^{3+}$ over $\mathrm{Cu}^{2+}$ (Table 2). This may be due to $\mathrm{Cu}^{2+}$ being a softer Lewis acid than $\mathrm{Fe}^{3+}$ and therefore having a lower affinity for hydroxypyridinones (HOPOs), which are hard Lewis bases, according to Pearson's hard-soft acid base theory (Pearson 1963).

\section{Distribution coefficients}

The distribution coefficients $\left(\log D_{7,4}\right)$ between an n-octanol phase and a HEPES-buffered aqueous phase at $\mathrm{pH} 7.4$ were determined for ligand C6 $\left(\log D_{7,4}=-1.71(7)\right)$ and its $\mathrm{Fe}^{3+}$ complex $\left(\log D_{7,4}=-0.18(2)\right)$ (Table 2). In the case of $\mathrm{C} 9$ and its $\mathrm{Fe}^{3+}$ complex, no significant decrease in the 
Table 2 Overall stability constants $(\log \beta)$, metal affinities at physiological $\mathrm{pH}(\mathrm{pM})$ and distribution coefficients $\left(\log D_{7.4}\right)$ for M-C6, M-C9, M-DFP and M-1,2HOPO complexes $\left(\mathrm{M}=\mathrm{Fe}^{3+}\right.$, $\left.\mathrm{Cu}^{2+}\right)$

\begin{tabular}{|c|c|c|c|c|c|c|c|c|}
\hline \multirow[t]{2}{*}{$\log \beta$} & \multicolumn{2}{|l|}{ C6 } & \multicolumn{2}{|l|}{ C9 } & \multicolumn{2}{|l|}{ DFP [58] } & \multicolumn{2}{|c|}{ 1,2-HOPO [59] } \\
\hline & $\mathrm{Fe}^{3+}$ & $\mathrm{Cu}^{2+}$ & $\mathrm{Fe}^{3+}$ & $\mathrm{Cu}^{2+}$ & $\mathrm{Fe}^{3+}$ & $\mathrm{Cu}^{2+}$ & $\mathrm{Fe}^{3+}$ & $\mathrm{Cu}^{2+}$ \\
\hline ML & $10.43(1)$ & $9.4(2)$ & $12.2(3)$ & $9.6(1)$ & $15.01(1)$ & $10.42(1)$ & $10.6(1) 3$ & $7.29(2)$ \\
\hline MLH & I & I & $13.66(2)$ & $12.6(2)$ & I & I & I & I \\
\hline ML2 & $20.11(2)$ & $15.8(2)$ & $21.2(2)$ & $15.4(2)$ & 27.3(1) & $19.09(1)$ & $20.1(2)$ & $13.06(4)$ \\
\hline ML2H & l & l & l & l & l & $21.98(8)$ & l & l \\
\hline ML2(OH)2 & $5.67(1)$ & I & $5.62(1)$ & l & l & $8.49(3)$ & l & I \\
\hline ML3 & $\begin{array}{l}28.05(2) \\
28.6^{\mathrm{a}}\end{array}$ & I & $\begin{array}{l}28.2(1) \\
28.1^{\mathrm{a}}\end{array}$ & I & $37.43(1)$ & I & $27.2(2)$ & I \\
\hline $\mathrm{pM}^{\mathrm{b}}$ & 18.5 & 11.6 & 18.4 & 11.1 & 19.3 & 10.5 & 16.1 & 6.9 \\
\hline $\log D_{7,4}$ & $-0.18(2)$ & I & $-1.8(6)$ & I & $-2.60(5)$ & & I & I \\
\hline
\end{tabular}

Solvent: $\mathrm{H}_{2} \mathrm{O} ; I=0.1 \mathrm{M}\left(\mathrm{NaClO}_{4}\right) ; T=25.0{ }^{\circ} \mathrm{C}, \beta_{\mathrm{ML} x \mathrm{H} y}=\left[\mathrm{ML}_{x} \mathrm{H}_{y}\right] /\left([\mathrm{M}][\mathrm{L}]^{x}[\mathrm{H}]^{y}\right)$; charges were omitted for the sake of clarity. The numbers given in parentheses correspond to the $\mathrm{SD}$, expressed to the last significant figure

${ }^{\text {a }}$ Values obtained from the competition experiments

${ }^{\mathrm{b}} \mathrm{pM}=-\log \left[\mathrm{M}_{\text {free }}\right]_{\text {total }},[\mathrm{pH}]=7.4,[\mathrm{~L}]=10^{-5} \mathrm{M},[\mathrm{M}]=10^{-6} \mathrm{M}$ (a)

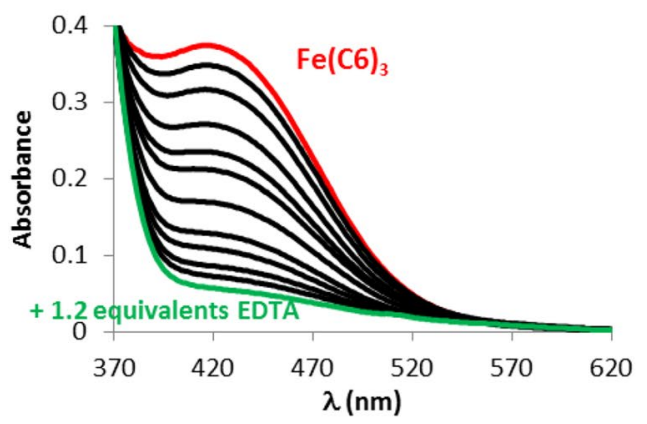

(b)

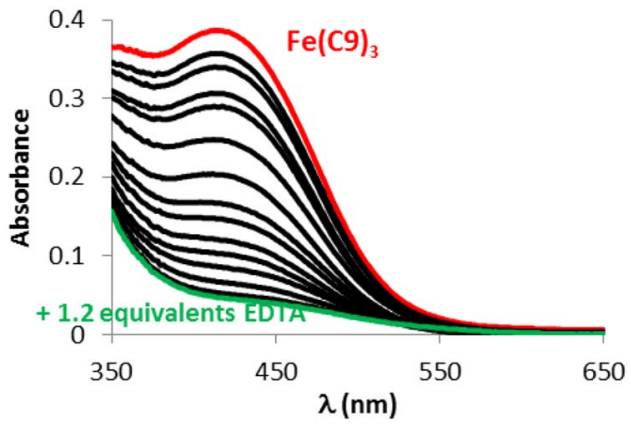

Fig. 3 Spectrophotometric batch (itration between $\mathrm{Fe}(\mathrm{C} 6)_{3}\left([\mathrm{C} 6]=3.65 \times 10^{-4} \mathrm{M}\right.$, $\left.[\mathrm{C} 6] /\left[\mathrm{Fe}^{3+}\right]=3.2\right)$ and EDTA $(0 \leq[$ EDTA $] /$ $\left.\left[\mathrm{Fe}(\mathrm{C} 6)_{3}\right] \leq 1.2\right)$, and $\mathbf{b} \mathrm{Fe}(\mathrm{C} 9)_{3}$ ([C9] $=3.54 \times 10^{-4} \mathrm{M},[\mathrm{C} 9] /$ $\left.\left[\mathrm{Fe}^{3+}\right]=3.2\right)$ and EDTA $\left(0 \leq[\mathrm{EDTA}] /\left[\mathrm{Fe}(\mathrm{C} 6)_{3}\right] \leq 1.2\right)$. Solvent: Hepes buffer $\mathrm{pH} 7.4$, $I=0.1 \mathrm{M}\left(\mathrm{NaClO}_{4}\right), T=25.0^{\circ} \mathrm{C}$ 
Fig. 4 Spectrophotometric titration versus $\mathrm{pH}$ of a $\mathrm{C} 6$ with $\mathrm{Cu}^{2+}\left([\mathrm{C} 6]=1.63 \times 10^{-4} \mathrm{M}\right.$, $\left.[\mathrm{C} 6] /\left[\mathrm{Cu}^{2+}\right]=2\right)$ and $\mathbf{b} \mathrm{C} 9$ with $\mathrm{Cu}^{2+}\left([\mathrm{C} 9]=1.48 \times 10^{-4} \mathrm{M}\right.$, $\left.[\mathrm{C} 9] /\left[\mathrm{Cu}^{2+}\right]=2\right)$. Electronic spectra of the $\mathrm{Cu}^{2+}$ complexes of $\mathbf{c}$ C6 and $\mathbf{d}$ C9. Distribution curves of the $\mathrm{Cu}^{2+}$ complexes of e C6 ([C6] $\left.=1.63 \times 10^{-4} \mathrm{M}\right)$ and $\mathbf{f}$ C9 $\left([\mathrm{C} 9]=1.48 \times 10^{-4} \mathrm{M}\right)$. Solvent: $\mathrm{H}_{2} \mathrm{O}, I=0.1 \mathrm{M}$ $\left(\mathrm{NaClO}_{4}\right), T=25^{\circ} \mathrm{C}$ for all measurements (a)

$$
L H_{n-1}+H \leftrightarrow L H_{n}
$$

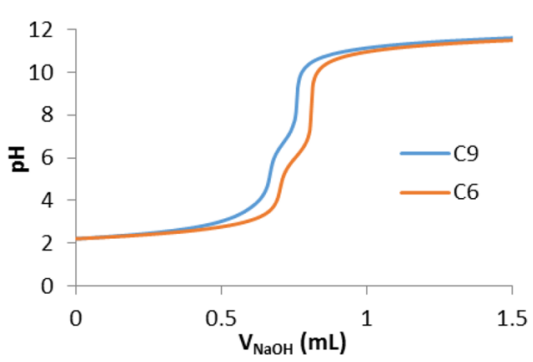

(c)

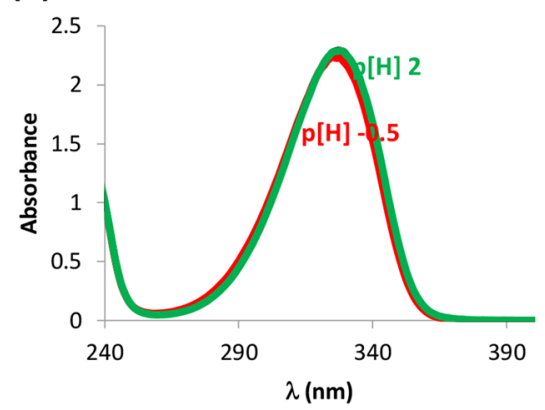

(e)

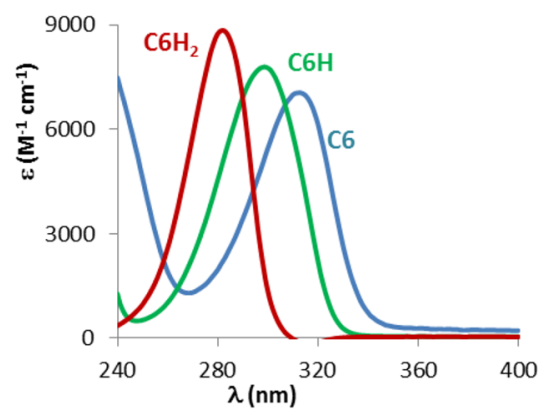

(b) $\quad K_{n}^{H}=\frac{\left[L H_{n}\right]}{\left[L H_{n-1}\right][H]}$

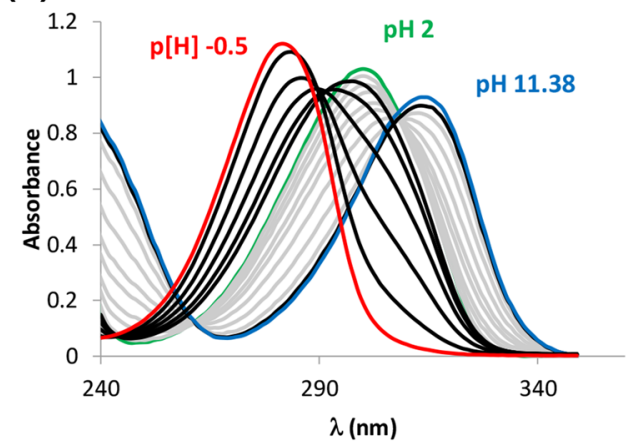

(d)

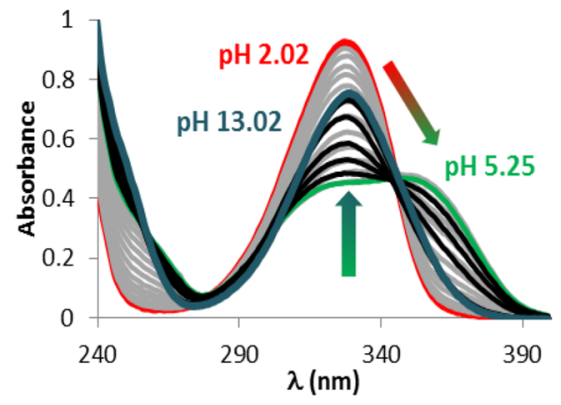

(f)

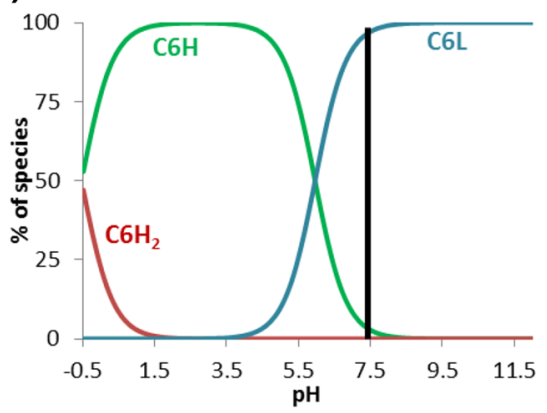

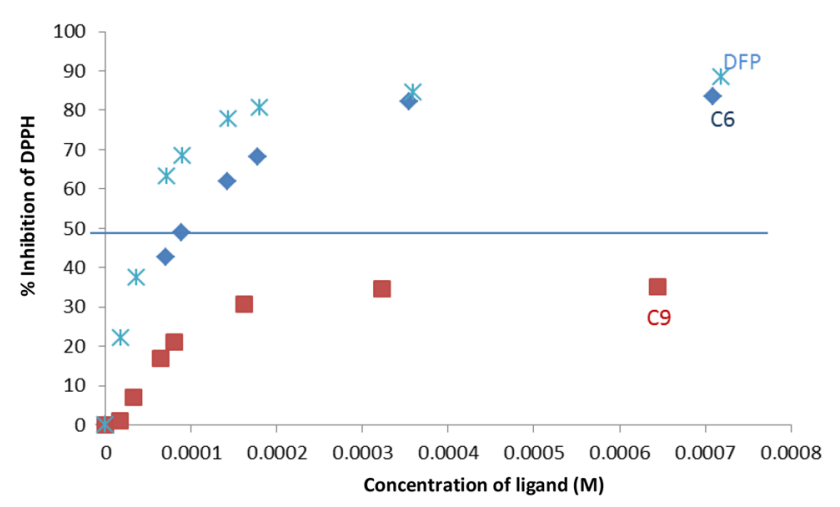

Fig. 5 Percentage inhibition of the DPPH radical by the iron chelators C6, C9 and DFP, at the steady state would be mainly due to the strong $\mathrm{Fe}^{3+}$ chelation ability of ligands $\mathrm{C} 6$ and $\mathrm{C} 9$ that inhibits the Fenton reaction, rather than from direct scavenging of $\mathrm{OH}^{\bullet}$ radicals. Furthermore, calculation of the $\mathrm{IC}_{50}$ values suggested strongly that the 1,2-HOPO based ligands $\mathrm{C} 6\left(\mathrm{IC}_{50}=0.74(1) \mathrm{mM}\right)$ and $\mathrm{C} 9$ $\left(\mathrm{IC}_{50}=0.61(1) \mathrm{mM}\right)$ function at least as efficiently as antioxidants such as DFP $\left(\mathrm{IC}_{50}=0.63(9) \mathrm{mM}\right)$.

\section{C6 and $\mathrm{C} 9$ treatment induces changes in neuronal labile metal content in lactacystin-treated SH-SY5Y cells}

The post-test analysis of total intracellular iron levels measured by ICP-MS revealed that the application of lactacystin to the cells produced a significant increase of $27.6 \pm 0.05 \%$ $(p=0.047)$ compared to untreated cells (Fig. 7a). However, lactacystin-treated cells, co-incubated with compound, restored iron levels to control levels. This was the case for 
Fig. 6 Percentage inhibition of deoxyribose degradation by the ligands a $\mathrm{C} 6$ and $\mathbf{b} \mathrm{C} 9$ in the presence of $\mathrm{FeCl}_{3}(\times)$ or FeEDTA (filled triangle) and distribution curves of $\mathrm{FeL}_{3}$ complexes versus ligand concentrations. Solvent: $20 \mathrm{mM}$ phosphate buffer $\mathrm{pH}$ $7.4,[\mathrm{Fe}]=[\mathrm{EDTA}]=0.1 \mathrm{mM}$, $0<$ [C6], [C9] $<3 \mathrm{mM}$

\section{(a)}

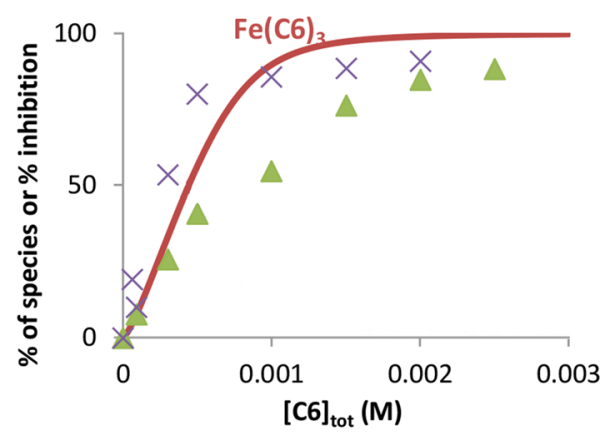

(b)

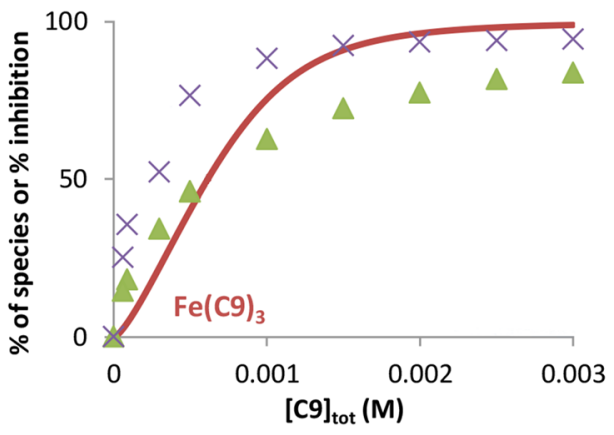

(a)

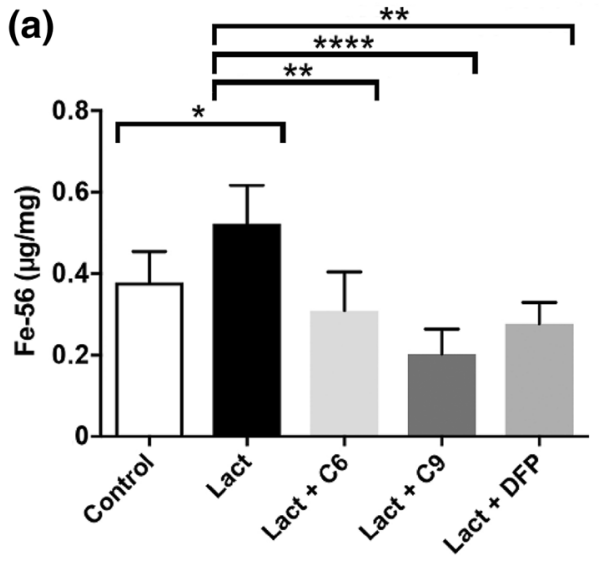

(c)

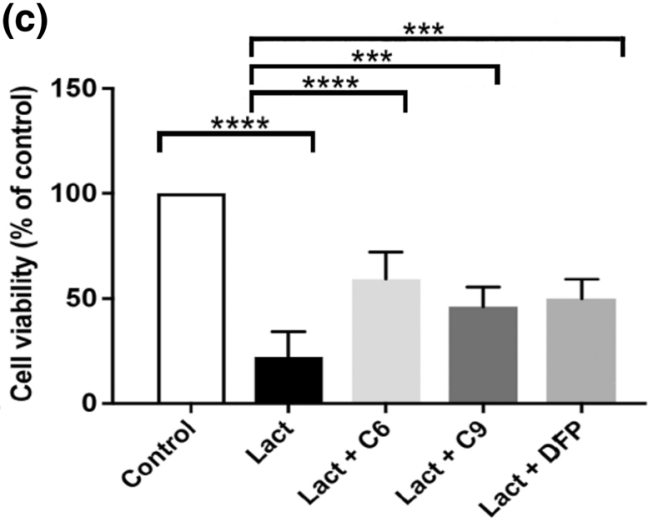

(b)

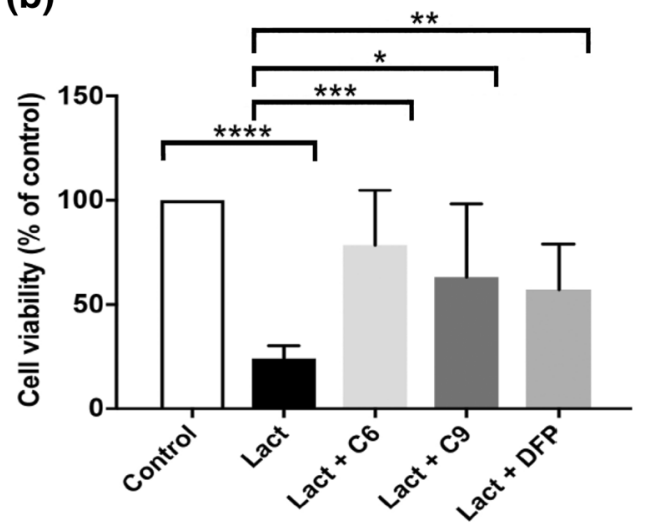

Fig. 7 a Iron levels, as measured by ICP-MS, following treatment of SH-SY5Y cells with lactacystin, were greatly increased; in contrast, all tested compounds reduced such levels to a range comparable to the non-toxin treated control cells. b Such iron chelation associated with neuroprotective activity shown by $\mathrm{C} 6$ and $\mathrm{C} 9$ against lactacystin-induced degeneration of SHSY-5Y cells. In the absence of any of the compounds, incubation with lactacystin $(5 \mu \mathrm{M})$ for $24 \mathrm{~h}$ decreased cell viability by $>75 \%$ (a, b). The compounds $(100 \mu \mathrm{M})$ protected against neurotoxin-mediated cell death (cell viability was increased by C6: $54.3 \%$, C9: $38.9 \%$ and DFP: $32.8 \%$, relative to the toxin-only condition), where treatment with $\mathrm{C} 6$ provided most protec- tion to the cells $(* * * p=0.0002)$. $\mathbf{c}$ Addition of C6 and C9, as well as DFP, also significantly rescued against such toxin-associated cell death. Cellular incubation with the two novel 1,2-HOPO derivatives or DFP (100 $\mu \mathrm{M}$ per compound) also rescued against lactacystininduced cell death (\% cell viability increases compared to toxinonly treatment were: C6: $37.2 \%$, C9: $24 \%$ and DFP: $28 \%$ ). The level of viable cells was measured at OD $490 \mathrm{~nm}$ using the CellTiter $96^{\circledR}$ AQueous One Solution Cell Proliferation Assay (MTS, Promega). Experiments were carried out $\times 3$ with each experiment done in triplicate. Data represent the mean $\pm \mathrm{SD}$ 
both C6 $(40.9 \pm 0.04 \%, p=0.003)$ and C9 $(61.1 \pm 0.03 \%$, $p=0.0001$ ), when compared to cells treated with lactacystin only. At the compounds' concentration used in this study $(100 \mu \mathrm{M})$, only C9 (and not C6) showed a greater capability than DFP for reducing accumulated iron in the toxin-treated cells, where C9 reduced the lactacystin-induced high iron levels by a further $26.5 \pm 0.03 \%(p=0.0028)$ compared to DFP treatment.

To eliminate the possibility that lactacystin indirectly altered iron through modulation of total metal homeostasis and to assess whether these compounds had a general chelating effect on other divalent metals, levels of copper and zinc were also measured in the same conditions (data not shown). Exposure to lactacystin decreased the cellular stores of copper $(46.5 \pm 0.004 \%)$ and zinc $(28.3 \pm 0.05 \%)$, but this change did not reach statistical significance. No statistical significance was observed upon treatment with either C6 (copper decreased by $1.3 \pm 0.003 \%$; zinc increased by $29 \pm 0.07 \%$ ) or C9 (copper decreased by $26.8 \pm 0.003 \%$; zinc $3.7 \pm 0.05 \%$ ) of the lactacystin-treated cells. This was comparable to data obtained for DFP (copper increased by $3.9 \pm 0.004 \%$; zinc $30 \pm 0.03 \%)$.

\section{Compound rescue and protection against lactacystin toxicity}

The potential of $\mathrm{C} 6$ and $\mathrm{C} 9$ to rescue and protect against lactacystin-induced neurotoxicity was compared to DFP in SH-SY5Y cell cultures. Rescue was evaluated by the addition of the compound (for $24 \mathrm{~h}$ ) after lactacystin exposure for $24 \mathrm{~h}$, whereas protection was tested by the application of compound (for $24 \mathrm{~h}$ ) prior to lactacystin (also for $24 \mathrm{~h}$ ). In each condition the negative control comprised of

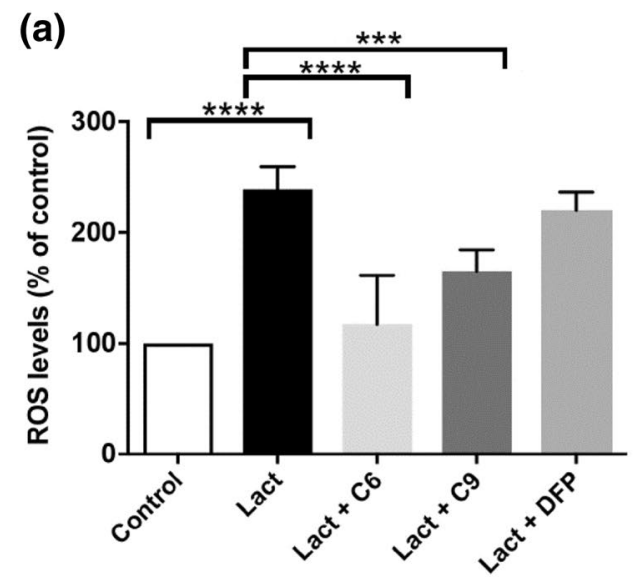

Fig. 8 Fluorescence intensity values of a iROS levels and b eROS levels revealed that treatment with C6 and C9 reduced iROS by $50.7 \%(* * * * p=0.0001)$ and $30.8 \%,(* * * p=0.0003)$, respectively. Addition of DFP did not produce a notable effect on lactacystininduced increased iROS levels. A similar pattern was detected for the compound-vehicle (dissolved in media) only. Lactacystin (in the absence of compound) reduced cell numbers compared to the untreated control cells, as seen in both the 'protection'-(by $75.8 \pm 6 \%, p<0.0001$ ) (Fig. 7b) and the 'rescue' assay (by $77.9 \pm 12 \%, p<0.0001$ ) (Fig. 7c). In lactacystin exposed cells, treatment with C6 significantly increased cell survival when administered either prior (by $54.3 \pm 20.3 \%$, $p=0.0002$ ) (Fig. 7b) or following (by $37.2 \pm 12.8 \%$, $p<0.0001$ ) (Fig. 7c) neurotoxin exposure. C9 also revealed significant protective (by $38.9 \pm 19.1 \%, p=0.0206$ ) (Fig. $7 \mathrm{~b}$ ) and rescue effects (by $24 \pm 9.3 \%, p=0.001$ ) (Fig. 7c) against lactacystin-induced cell death. A similar neuroprotection (by $32.8 \pm 22 \%, p=0.004$ ) (Fig. 7b) and neurorescue profile $(28 \pm 9.1 \%, p=0.0002)$ (Fig. 7c) as the two test compounds was observed with assessment of the known clinical chelating compound, DFP.

\section{C6 and $C 9$ reduce lactacystin-induced production of intracellular and extracellular ROS}

Levels of ROS produced intracellularly (iROS) or extracellularly (eROS) were measured upon lactacystin treatment, followed by treatment with a compound of interest. Without addition of the compound, lactacystin-treated cells had a significant increase in levels of iROS $(139 \pm 20.5 \%, p<0.0001)$ (Fig. 8a) and eROS $(106 \pm 27.3 \%, p<0.0001)$ (Fig. 8b), compared to untreated control cells. The addition of $\mathrm{C} 6$ to the toxin model produced a significant reduction in iROS $(121.2 \pm 43.5 \%, p=0.0002)$ (Fig. 8a) and eROS $(97.9 \pm 34 \%$, $p=0.0102$ ) (Fig. 8b). This rescue effect was less so with addition of C9 [iROS: $74 \pm 19 \%, p=0.0002$ (Fig. 8a); eROS: $78 \pm 60.6 \%, p=0.0102$ ) (Fig. $8 b$ )]. Intriguingly, the clinically available compound DFP was unable to exert

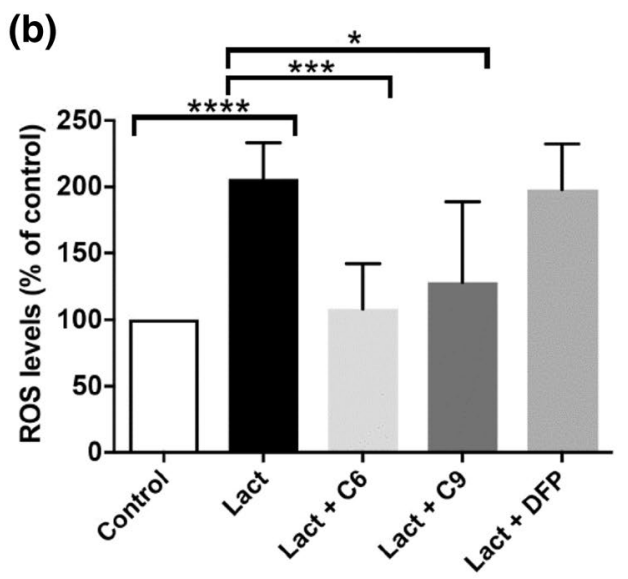

eROS levels, detected in the cell culture medium. Here, the addition of C6 $(47.5 \%, * * *=0.0005)$ and C9 $(37.8 \%, * * p=0.0066)$ resulted in a significant reduction in the lactacystin-induced elevated eROS levels 
a significant reducing effect on either iROS $(19 \pm 16.7 \%$, $p=0.2894)$ (Fig. 8a) or eROS levels $(8 \pm 34.5 \%, p=0.7637)$ (Fig. 8b) that were increased by treatment with lactacystin.

\section{C6 and $C 9$ reduce lactacystin-induced $a-S Y N$ overexpression levels}

Endogenously expressed $\alpha-\mathrm{SYN}$ in SH-SY5Y cells was upregulated by incubation with lactacystin for $24 \mathrm{~h}$ $(17.8 \pm 0.18 \%, p<0.0001)$ (Fig. 9). This response was negated by post-treatment with the compounds of interest, producing a significant response with C6 $(13.5 \pm 0.3 \%$, $p=0.0163)$ and DFP $(25.8 \pm 0.03 \%, p<0.0001)$, while C9 produced the most striking reduction in lactacystin-induced $\alpha$-SYN protein levels $(43.5 \pm 0.08 \%, p<0.0001)$ (Fig. 9).

\section{NMR spectroscopy}

The interaction of lactacystin with C6 was studied in both DMSO- $d_{6}$ and $10 \%$ DMSO- $d_{6}$ in $\mathrm{D}_{2} \mathrm{O}$ in the absence and presence of PBS (with osmolarity, ion concentration and a $\mathrm{pH}$ of 7.4). This buffer was added to replicate the more physiologically relevant environment of the SH-SY5Y cells. Reference spectra of both C6 and lactacystin were first obtained in each of these solvent systems. Resonances due to lactacystin were assigned by comparing values to previously published ${ }^{1} \mathrm{H}$ NMR data (Hayes et al. 2008).

Upon addition of 1 equivalent of $\mathrm{C} 6$ to a solution of lactacystin in DMSO- $d_{6}$, no spectral changes were observed, suggesting there was no formation of the lactacystin-C6 adduct. Further additions of $\mathrm{C} 6$ (up to a total of 3 equivalents) again did not lead to the appearance of any new resonances for the lactacystin-C6 adduct, with only the resonances for lactacystin and $\mathrm{C} 6$ being observed. When the NMR experiments were conducted in $10 \%$ DMSO- $d_{6}$ in $\mathrm{D}_{2} \mathrm{O}$, no spectral changes were observed. Similarly, addition of PBS to raise the $\mathrm{pH}$ also did not lead to any spectral changes and there was no evidence for formation of either the clasto-lactacystin $\beta$-lactone or the lactacystin-C6 adduct. Finally, no new resonances were observed upon addition of three equivalents of C6 to lactacystin, and this was also the case in the presence of phosphate buffer. MS analysis of the solutions from both solvent systems (data not shown) did not show the expected mass peaks due to the lactacystin-C6 adduct, confirming that there was no interaction between lactacystin and $\mathrm{C} 6$ under these conditions.

Should the lactacystin-C6 adduct have been formed (assuming that the hydroxymethyl group is the most nucleophilic group in C6, see the discussion section), a new set of resonances for the three aromatic protons, and a new set of doublets for the methyl groups would be expected. In addition, the diastereotopic methylene protons would be expected to appear as a pair of doublets centered at ca. $4.5 \mathrm{ppm}$ (parts per million).

\section{Discussion}

The aim of the present study was to combine physicochemical characterization and cellular investigation of the treatment effects of two novel 1,2-HOPOs, C6 and C9, that were produced in our lab, in a lactacystin cellular model of PD, with this model replicating key changes seen in both neurotoxin animal models of the disease and also post-mortem PD brains. As a first-in class inhibitor of the UPS, the mechanism that controls cell turnover and regulates protein catabolism in the mammalian cytosol and nucleus, lactacystin exposure has been demonstrated as an experimentally useful tool for mimicking aspects of neurodegenerative diseases that display deficits in clearing misfolded proteins, to lead to intracellular protein aggregation, cytotoxicity, and
Fig. 9 Relative density of the western blots showing $\alpha$-SYN expression in SH-SY5Y cells treated with lactacystin $(5 \mu \mathrm{M})$, followed by $100 \mu \mathrm{M}$ treatment with either C6 $(n=3)$, C9 $(n=3)$ or DFP $(n=3)$. The insert shows a representative blot. $\alpha$-SYN band intensities are reported as relative expression levels of $\alpha$-SYN compared to GAPDH. C9 treatment induced the most significant $\alpha$-SYN downregulation in lactacystintreated SH-SY5Y cells

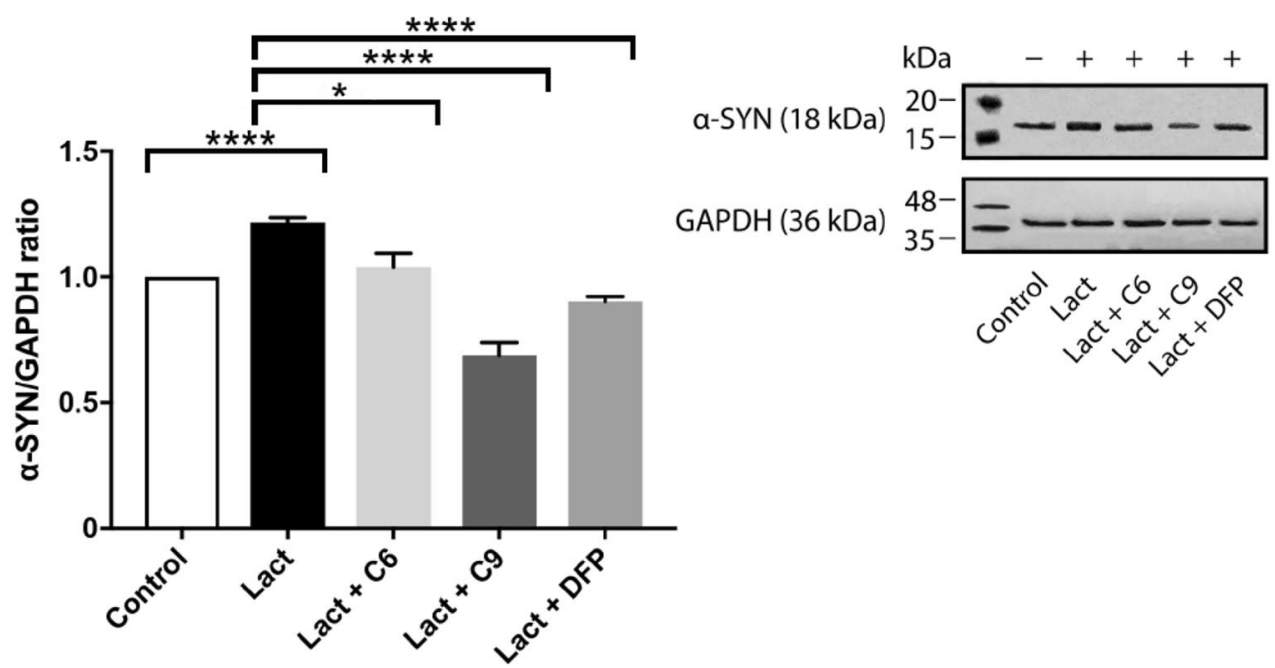


eventual cell death (Konieczny et al. 2014; Harrison et al. 2015; Fenteany et al. 1995).

We compared the results obtained from testing C6 and C9 to the clinically available oral iron chelator, DFP. This clinically licensed bidentate ferric chelator has been successfully used for over 2 decades against iron storage pathologies, including recent promising results achieved in a clinical phase-I trial conducted on a small cohort of PD patients, to reveal beneficial effect on patients' motor symptoms (Moreau et al. 2018). Our results reveal that C6 and C9 are capable of protecting and rescuing against lactacystininduced neuronal death, with our results implying strongly that the mechanism relates to the compounds' ability to reduce levels of labile iron, which leads to reduced levels of ROS, as well as the ability to reduce abnormally high levels of $\alpha$-SYN that the compounds mediated in the SH-SY5Y lactacystin cell model of PD.

Here we provide several lines of evidence for the ability by lactacysin to reduce the intracellular labile iron pool, and also demonstrate the ability of the novel compounds $\mathrm{C} 6$ and $\mathrm{C} 9$ to interact with $\mathrm{Fe}^{3+}$ and thereby restore iron levels. This includes measuring intracellular levels of Fe-56 (the most common isotope of iron) via ICP-MS, which revealed that application of lactacystin to the cells significantly increased iron content compared to untreated cells. In contrast, the same measures showed that all the tested compounds reduced the toxin-induced iron accumulation in cells. Moreover, general agreement exists that a build-up of intracellular iron stimulates oxidative stress, and hence that iron accumulation, followed by oxidative stress typically precedes all other cellular changes, including changes in iron storage proteins (Devos et al. 2014). In this regard our results also show elevated levels of both iROS and eROS upon lactacystin treatment compared to toxin untreated control cells, while administration of both novel compounds, but particularly C6, exerted a significant iROS and eROS reducing effect. The association between lactacystin and the molecular mechanisms responsible for absorption of iron and maintenance of iron homeostasis, as well as how our novel compounds might interact with these factors to restore iron homeostasis in this toxin model of PD, will require further investigation. Several iron response proteins have been identified, including ferritin (FT), a protein for binding and carrying iron mainly in the blood serum; mitoferrin-2 (Mfrn2), for importing iron into mitochondria, the iron exporter ferroportin (FPN) and also hepatocyte-secreted hormone (Hepc), an iron absorption inhibitor mainly produced by the liver (Finberg 2013; Wallace 2016). Previously published work provided insight into the interactions between lactacystin and some of these molecular iron regulators. In differentiated SH-SY5Y cells exposed to lactacystin, Carroll and others (2011) reported no change in protein expression levels of either TfR or FT, but saw upregulation for FPN and Mfrn2 protein, but without concomitant changes in associated mRNA levels. This result, showing largely a lack of change in several known iron regulatory proteins, and inconsistency between changes at the transcription versus translation level for regulators that were altered, suggests that other factors such as increased labile iron and accumulation of oxidatively damaged proteins may rather account for lactacysin-induced cell death. Greater insight to better understand the nature of the molecular interactions between this UPS toxin and the elaborate mechanisms that have evolved to sense iron levels and adjust iron absorption and recycling to maintain iron homeostasis could deliver new diagnostic and therapeutic possibilities for iron-related disorders. However, such further studies may be best placed by utilizing an in vivo system, since the balance of iron homeostasis is maintained through a dynamic equilibrium between systemic tissues, and hence an animal system will allow for a comparison between various body compartments, while molecular iron regulators identified so far have been shown to operate in man as well as rodents (Wallace 2016). In this regard, our previous work showed that rats that had received a unilateral nigral stereotaxic injection of lactacystin accurately mirror the behavioural and neuropathological deficits shown by PD patients (Pienaar et al. 2015a, b; Sharma et al. 2020).

Also, in a previous study (Workman et al. 2015) we showed that in SH-SY5Y cells pre-incubated with $50 \mu \mathrm{M}$ of iron, subsequent exposure to either C6 or DFP changed protein expression levels of FT and TfR to levels seen in cells not treated with iron, while a non-iron binding control compound left the FT and TfR levels unaltered. Future experiments are warranted to identify all genes/protein products involved in the complex pathway devoted to iron regulation that $\mathrm{C} 6, \mathrm{C} 9$ (and clinically available DFP) can alter downstream of their capacity to bind iron and restore toxin-induced ROS, with most insight that may come from screens conducted in animals with targeted mutations in iron regulatory genes.

Although it remains unclear whether changes in iron regulatory proteins translates into an actual change in cellular iron content, such mechanistic studies will further understanding as to the downstream implications that follow a UPS impairment as a stimulus for iron overload as seen in PD-affected brains that may contribute to neuronal death. On the other hand, detailing the iron protein response network following exposure to a 1,2-HOPO iron chelator such as C6 or $\mathrm{C} 9$, will further enlighten on the mechanistic basis for the protective response to lactacystin exposure that our data demonstrates.

The ligands C6, C9 and DFP differed in their respective metal coordination abilities and in their relative acidities, resulting in different metal-complex stability constants and hence this line of investigation was unable to afford a rationale for their pro-survival effects seen in this neurotoxin 
cell model. We thus calculated the respective $\mathrm{pM}$ values to represent the amount of free metal in solution at physiological $\mathrm{pH}$, allowing us to compare the chelation power for various metals bound by the different ligands assessed in this study. The substituents present in C6 and C9 induced an increase of their affinity towards $\mathrm{Fe}^{3+}$ by one order of magnitude compared to DFP. Both $\mathrm{pFe}$ values lay below those observed for transferrin $(\mathrm{pFe}=23.62)$ so that, similar to DFP, C6 and C9 would therefore be expected to donate chelated iron to unsaturated transferrin, thus avoiding a loss of total iron and favoring its repositioning to other sites of use. This is similar to DFP, which was demonstrated as chelating excess intracellular labile iron and then redistribute it to extracellular apotransferrin (Sohn et al. 2008, 2011). This finding could suggest that, despite their relatively low protonation constants, C6 and C9 exerted their neuroprotective and neurorescue effects in the lactacystin cellular model of PD by entering into SH-SY5Y cells, and then chelating intracellular labile $\mathrm{Fe}^{3+}$, a suggestion that is in agreement with our previous study which showed that both $\mathrm{C} 6$ and $\mathrm{C} 9$ reduced intracellular $\mathrm{Fe}^{3+}$ levels in similar cells in the 6-OHDA in vitro model of PD (Workman et al. 2015). However, it is also possible that C6 and C9 exerted their neuroprotective and neurorescue effects simply by chelating extracellular labile $\mathrm{Fe}^{3+}$ instead. This depletion in extracellular labile $\mathrm{Fe}^{3+}$ would re-adjust the equilibrium between extracellular and intracellular labile $\mathrm{Fe}^{3+}$ and would reduce apotransferrin-mediated influx of $\mathrm{Fe}^{3+}$ into the cell, leading to a net reduction in the intracellular labile $\mathrm{Fe}^{3+}$. In addition, whilst the low protonation constants of $\mathrm{C} 6$ and $\mathrm{C} 9$ suggest that neither compound is significantly capable of crossing into the SH-SY5Y cells through passive diffusion, we cannot rule out the possibility that these compounds could enter the cells as the neutral complex of other metals such as $\mathrm{Mg}^{2+}$ or $\mathrm{Zn}^{2+}$ or via an active transport mechanism (e.g., via a glucose transporter protein anchored in the cell membrane).

Distribution diagrams show that at physiological $\mathrm{pH}$, C6 exist as neutral $\mathrm{Fe}(\mathrm{C} 6)_{3}$, in accordance with $\log \mathrm{D}_{7,4}$ values of $-0.18(2)$, suggesting a less hydrophilic complex than DFP at a $\log D_{7,4}$ of -2.60(5)) (Hayes et al. 2008). At similar conditions, ligand $\mathrm{C} 9$ existed as $\mathrm{Fe}(\mathrm{C} 9)_{3}{ }^{3-}$ and did not show significant migration to the $n$-octanol phase in our partition experiments, thus precluding the determination of its $\log D_{7,4}$ value. This finding indicates its highly hydrophilic nature and suggests that the neutral, relatively hydrophobic $\mathrm{Fe}(\mathrm{C} 6)_{3}$ complex would be able to leave the cell via passive diffusion and underscores that redistribution of $\mathrm{Fe}^{3+}$ between cells is likely. On the other hand, the charged $\mathrm{Fe}(\mathrm{C} 9)_{3}{ }^{3-}$ complex would be highly unlikely to do so.

The DAergic cell death that characterizes PD pathology is underpinned by oxidative stress, concomitant with cellular metabolic impairment (Halliwell and Gutteridge 1984). Amongst other cell death mechanisms, lactacystin instigates a marked increase in oxidative stress and metabolic failure, thereby modeling cellular effects seen in PD, with one study reporting that lactacystin treatment increased ROS production, which subsequently induced mitochondrial cytochrome $c$ release indirectly, via translocation of the Bax protein, ultimately resulting in cell death (Perez-Alvarez et al. 2009). Iron is a potent generator of free-radicals via the Haber-Weiss reactions. In this regard, it is well documented that UPS impairment, as instigated by application of lactacystin, results in excessive iron, which in turn increases oxidative stress via overproduction of ROS (Halliwell and Gutteridge 1984; Dixon and Stockwell 2014). In turn, these events impair proteasomal function, thus promoting protein aggregates that result in eventual cell death (Rhodes and Ritz 2008).

Our data reveals that C6 treatment produced a greater reduction in $\mathrm{R} O S$ and eROS in lactacystin-treated cells than when cells were treated with C9. In addition, evaluation of the ability of $\mathrm{C} 6$ and $\mathrm{C} 9$ to act as radical traps using the DPPH assay revealed that $\mathrm{C} 6$ reached a much better efficiency than $\mathrm{C} 9$, with $\mathrm{C} 6$ being nearly as efficient as DFP. It was found that 3-hydroxy-4(1H)-pyridinone derivatives, including DFP, are poor radical scavengers (Rhodes and Ritz 2008; Kayyali et al. 1998). Their ability to protect cells against oxidative damage is therefore not thought to be linked to the trapping of ROS. In fact, it was found that such metal chelators are effective at preventing $\mathrm{Fe}^{3+}$ from taking part in Haber-Weiss reactions, but also that the inhibition is stoichiometry dependent, requiring an $\mathrm{FeL}_{3}$ complex for inactivation ( $\mathrm{L}=$ ligand) (El-Jammal and Templeton 1996; Merkofer et al. 2004, 2006; Devanur et al. 2008; Chaves et al. 2012). Their mode of action therefore appears to rather be linked to redox silencing of metals. It is also known that catechol groups (present in DA and L-DOPA) are pro-oxidants in the presence of metals, with DFP that was found capable of preventing the pro-oxidant effect of this combination (Sun et al. 2018), thereby indicating multiple beneficial mechanisms of action.

Lactacystin's neurotoxic mechanism of action relates to the covalent bond it forms with specific catalytic subunits of the 20S catalytic core of the proteasome, believed to regulate critical aspects for recognising and unfolding ubiquitinated proteins. This binding inhibits multiple peptidase activities of the enzyme complex, resulting in lack of proteasomal activity (Tomoda and Omura 2000). Based on this known mode of action of lactacystin, we postulated that besides iron chelation and an anti-ROS effect, C6 could potentially play an alternative role in protecting SH-SY5Y cells from lactacystin-induced neuronal damage, ultimately resulting in cell death, similar to what is seen in SNpc DAergic neurons in PD-affected human brains. In this regard we reasoned that the primary hydroxyl group of C6 could trap the reactive clasto-lactacystin $\beta$-lactone intermediate intracellularly, to 
form the far less reactive lactacystin-C6 adduct, which is unable to acylate the $\mathrm{N}$-terminal threonine residue in the $20 \mathrm{~S}$ subunit of the proteasome. A similar nucleophilic attack by the $N$-hydroxyl group of C6 would only form an activated ester that would maintain the reactivity and therefore biological action of clasto-lactacystin $\beta$-lactone (Finkelstein et al. 2017). Thus, in addition to chelating and passivating intracellular iron, C6 could potentially act as a sacrificial compound that inactivates the reactive clasto-lactacystin $\beta$-lactone intermediate formed by lactacystin.

Accordingly, we assessed via ${ }^{1} \mathrm{H}$ NMR whether the neuronal protection and rescue effect we observed here in lactacystin-treated cell cultures co-incubated with the novel iron chelators was due to the formation of an adduct between C6 and lactacystin. In view of the novel compounds offering a potential treatment of $\mathrm{PD}$, it was necessary to demonstrate that C6 is capable of preventing oxidative damage to neurons regardless of which toxin in vitro model is used for generating excessive levels of ROS (e.g., 6-OHDA, MPTP or lactacystin). In due regard, the NMR and MS experimental data indicates that $\mathrm{C} 6$ is not capable of chemically degrading lactacystin in this manner. This suggests that in the presence of C6, lactacystin is not deactivated and remains capable of producing ROS and that $\mathrm{C} 6$ protects neurons against oxidative stress-mediated neurodegeneration, regardless of the PD toxin used to generate excessive ROS for modeling PD-like cells. Since it appears that C6 does not degrade lactacystin, a similar NMR study on the interaction of lactacystin with C9 was not carried out in the present report.

Due to the interplay previously shown to exist between iron and $\alpha$-SYN accumulation and aggregation (Golts et al. 2002), iron chelators have been deemed a promising therapeutic strategy for reducing levels of $\alpha$-SYN pathology seen in PD-affected brains. The current results showed that C6 could normalise $\alpha$-SYN levels that had been increased due to lactacystin treatment, while DFP and C9 were capable of reducing $\alpha$-SYN levels substantially below the normal state, with C9 showing the most potent effect in this regard.

Our results show the therapeutic potential of the novel iron chelators, where it is well established that $\alpha$-SYN aggregation, as seen in PD brains, can be promoted by excess iron (Xiao et al. 2018). The central role that iron plays in LB promotion was further underlined by work reporting iron co-localization within LBs in the brains of PD patients (Castellani et al. 2000). The ability of metal-chelators such as PBT434, a novel quinazolinone compound bearing a metal-binding motif that holds moderate affinity, to prevent iron-mediated $\alpha$-SYN toxicity, had previously been demonstrated (Finkelstein et al. 2017). In this study, Finkelstein and others also revealed effective reduction of insoluble $\alpha$-SYN levels in brain lysates taken from mice harboring the A53T $\alpha-S Y N$ mutation that had been treated with the iron chelator clioquinol, compared to placebo-treated control mice.
In the current study we demonstrate the ability of DFP to reduce abnormally high levels of $\alpha-\mathrm{SYN}$ in the SH-SY5Y lactacystin cell model of PD. This result adds to recent data showing that DFP is capable of reducing $\alpha$-SYN aggregation in the hippocampi and cortices of transgenic mice bearing the A53T $\alpha$-SYN mutation, with such mice that had been fed iron for exacerbating the motor phenotype (Carboni et al. 2017). However, the protein reduction effect was weak, with significant variance detected between the mice.

Future investigations to identify the toxic nature of $\alpha$-SYN induced by lactacystin, and to determine at what stage the test compounds, relative to DFP, may interfere in organized fibril assembly, sequencing as the formation of dimers, oligomers, protofibrillar structures and eventual mature linear fibers, may further enlighten on the therapeutic mechanism by which the presently tested novel iron chelators showed ability to clear such protein abundance. Such additional characterisations, for example by utilizing immunoelectron microscopy, will strengthen the view proposed by the current data, that $\alpha$-SYN accumulation is a target for C9 especially. In addition, studies to determine the capacity of C6 and C9, relative to DFP, to reduce other PD-relevant, aggregate-prone proteins such as ubiquitin, where lactacystin had been shown to induce ubiquitinated protein aggregation in vitro (Yang et al. 2005), will give further insights as to how these novel iron chelators might act as agents inducing deubiquitination or for degrading aggregated intracellular proteins.

Work to determine the sequence of steps by which lactacystin exposure produces toxic forms of intracellular protein also promises to enlighten on the mechanism of protein accumulation, where such insight will help develop this in vitro PD model for reflecting aspects of PD. In this regard, its currently unknown whether lactacystin induces a primary event that leads to aggregation of $\alpha-S Y N$ due to its proteasome inhibitor effect, or whether this post-translational modification might rather occur firstly as a result of the reaction of lactacystin-induced excessive ROS production with $\alpha-S Y N$.

\section{Conclusions}

For improving our understanding of the therapeutic mechanisms of two novel 1,2-HOPO iron chelators (C6 and C9), we reveal, for the first time, their ability to both partially prevent and rescue against cell death due to lactacystininduced UPS inhibition, as was determined in an in vitro model of PD. We further revealed that such mitigating effects on the toxin-treated cells are likely due to the ability of the compounds to chelate and passivate intracellular labile iron, thereby reducing ROS production (accumulating both intracellularly and extracellularly) and prevent protein 
aggregation, both of which are neuropathological hallmarks of the cellular dysfunction seen in PD. Direct trapping of the reactive clasto-lactacystin $\beta$-lactone intermediate by $\mathrm{C} 6$ was not observed by NMR spectroscopy. Measurement of the stability constant values for $\mathrm{Fe}^{3+}$ and $\mathrm{Cu}^{2+}$ complexes confirmed that each of the compounds have a good affinity and selectivity for $\mathrm{Fe}^{3+}$. Our results provide further evidence in support of labile iron as a viable therapeutic target and justifies further development of iron chelators as potential therapies for treating PD. Thus, our results suggest that 1,2HOPO chelators are a valuable class to explore further as potential disease-modifying agents against $\mathrm{PD}$, in addition to 3-hydroxy-4(1H)-pyridinones.

Acknowledgements The authors wish to thank Chris Bradford for excellent technical assistance rendered during the experimental work presented in this paper. We gratefully acknowledge the Royal Society of Chemistry for awarding a Researcher Mobility Grant to FWL (Grant number KE2466).

Author contributions ISP and FWL conceived the original experimental research idea and designed the lactacystin-based experiments using the compounds $\mathrm{C} 6$ and $\mathrm{C} 9$ designed and previously published by DT. FWL, SF, JB, MS, JLE and ISP performed all experiments, provided funding for the experimental work and analysed the data. All authors wrote and reviewed the final version of the manuscript.

\section{Compliance with ethical standards}

Conflict of interest The authors declare that they have no conflict of interest.

Open Access This article is licensed under a Creative Commons Attribution 4.0 International License, which permits use, sharing, adaptation, distribution and reproduction in any medium or format, as long as you give appropriate credit to the original author(s) and the source, provide a link to the Creative Commons licence, and indicate if changes were made. The images or other third party material in this article are included in the article's Creative Commons licence, unless indicated otherwise in a credit line to the material. If material is not included in the article's Creative Commons licence and your intended use is not permitted by statutory regulation or exceeds the permitted use, you will need to obtain permission directly from the copyright holder. To view a copy of this licence, visit http://creativecommons.org/licenses/by/4.0/.

\section{References}

Abeliovich A et al (2000) Mice lacking alpha-synuclein display functional deficits in the nigrostriatal dopamine system. Neuron 25:239-252

Alberio T, Lopiano L, Fasano M (2012) Cellular models to investigate biochemical pathways in Parkinson's disease. FEBS J 279:1146-1155

Alderighi L, Gans P, Lenco A, Peters D, Sabatini A, Vacca A (1999) Hyperquad simulation and speciation (HySS): a utility program for the investigation of equilibria involving soluble and partially soluble species. Coord Chem Rev 184:311-318

Blois MS (1958) Antioxidant determinations by the use of a stable free radical. Nature 181:1199-1200
Braak H, Del Tredici K, Rüb U, de Vos RA, Jansen Steur EN, Braak E (2003) Staging of brain pathology related to sporadic Parkinson's disease. Neurobiol Aging 24:197-211

Carboni E et al (2017) Deferiprone rescues behavioral deficits induced by mild iron exposure in a mouse model of alpha-synuclein aggregation. Neuromol Med 19:309-321

Carroll CB, Zeissler M-L, Chadborn N, Gibson K, Williams G, Zajicek JP, Morrison KE, Hanemann CO (2011) Changes in iron-regulatory gene expression occur in human cell culture models of Parkinson's disease. Neurochem Int 59:76-80

Castellani RJ, Siedlak SL, Perry G, Smith MA (2000) Sequestration of iron by Lewy bodies in Parkinson's disease. Acta Neuropath 100:111-114

Chaves S, Canário S, Carrasco MP, Mira L, Amélia Santos M (2012) Hydroxy(thio)pyrone and hydroxy(thio)pyridinone iron chelators: physico-chemical properties and anti-oxidant activity. J Inorg Biochem 114:38-46

Das M, Yi DK, An SSA (2015) Analyses of protein corona on bare and silica-coated gold nanorods against four mammalian cells. Int $\mathrm{J}$ Nanomed 10:1521-1545

Devanur LD, Neubert H, Hider RC (2008) The Fenton activity of iron(III) in the presence of deferiprone. J Pharm Sci 97:1454-1467

Devos D et al (2014) Targeting chelatable iron as a therapeutic modality in Parkinson's disease. Antiox Redox Signal 21:195-210

Dixon SJ, Stockwell BR (2014) The role of iron and reactive oxygen species in cell death. Nat Chem Biol 10:9-17

Duce JA et al (2010) Iron-export ferroxidase activity of $\beta$-amyloid precursor protein is inhibited by zinc in Alzheimer's disease. Cell 142:857-867

El-Jammal A, Templeton DM (1996) Iron-hydroxypyridone redox chemistry: kinetic and thermodynamic limitations to Fenton activity. Inorg Chim Acta 245:199-207

Fenteany G, Standaert RF, Lane WS, Choi S, Corey EJ, Schreiber SL (1995) Inhibition of proteasome activities and subunit-specific amino-terminal threonine modification by lactacystin. Science 268:726-731

Finberg KE (2013) Regulation of systemic iron homeostasis. Curr Opin Hematol 20:208-214

Finkelstein DI et al (2017) The novel compound PBT434 prevents iron mediated neurodegeneration and alpha-synuclein toxicity in multiple models of Parkinson's disease. Acta Neuropathol Commun 5:53

Fish WW (1988) Rapid colorimetric micromethod for the quantitation of complexed iron in biological samples. Methods Enzymol 158:357-364

Gans P, Sabatini A, Macca A (1996) Investigation of equilibria in solution. Determination of equilibrium constants with the HYPERQUAD suite of programs. Talanta 43:1739-1753

Gardner JN, Katritzky AR (1957) N-oxides and related compounds. Part V. The tautomerism of 2- and 4-amino- and -hydroxy-pyridine 1-oxide. J Chem Soc. https://doi.org/10.1039/JR9570004375

Gillet R et al (2017) A bispidol chelator with a phosphonate pendant arm: synthesis, $\mathrm{Cu}(\mathrm{II})$ complexation, and $64 \mathrm{Cu}$ labeling. Inorg Chem 56:11738-11752

Golts N, Snyder H, Frasier M, Theisler C, Choi P, Wolozin B (2002) Magnesium inhibits spontaneous and iron-induced aggregation of alpha-synuclein. J Biol Chem 277:16116-16123

Halliwell B, Gutteridge JMC (1984) Oxygen toxicity, oxygen radicals, transition metals and disease. Biochem J 219:1-14

Harrison IF, Crum WR, Vernon AC, Dexter DT (2015) Neurorestoration induced by the HDAC inhibitor sodium valproate in the lactacystin model of Parkinson's is associated with histone acetylation and up-regulation of neurotrophic factors. $\mathrm{Br} \mathrm{J}$ Pharmacol 172:4200-4215

Hayes CJ et al (2008) Enantioselective total synthesis of omuralide, 7-epi-omuralide, and (+)-lactacystin. J Org Chem 73:2041-2051 
Kayyali R, Pannala AS, Khodr H, Hider RC (1998) Comparative radical scavenging ability of bidentate iron(III) chelators. Biochem Pharmacol 55:1327-1332

Kirchner T, Möller S, Klinger M, Solbach W, Laskay T, Behnen M (2012) The impact of various reactive oxygen species on the formation of neutrophil extracellular traps. Mediat Inflamm 2012:849136

Konieczny J et al (2014) Lack of neuroprotective effect of celastrol under conditions of proteasome inhibition by lactacystin in in vitro and in vivo studies: implications for Parkinson's disease. Neurotox Res 26:255-273

Lorenc-Koci E et al (2011) Different effects of intranigral and intrastriatal administration of the proteasome inhibitor lactacystin on typical neurochemical and histological markers of Parkinson's disease in rats. Neurochem Int 58:839-849

Ma Y, Roy S, Kong X, Chen Y, Liu D, Hider RC (2012) Design and synthesis of fluorinated iron chelators for metabolic study and brain uptake. J Med Chem 55:2185-2195

Mastroberardino PG et al (2009) A novel transferrin/TfR2-mediated mitochondrial iron transport system is disrupted in Parkinson's disease. Neurobiol Dis 34:417-431

McNaught KS, Björklund LM, Belizaire R, Isacson O, Jenner P, Olanow CW (2002) Proteasome inhibition causes nigral degeneration with inclusion bodies in rats. NeuroReport 13:1437-1441

Meng XQ et al (2016) Solanine-induced reactive oxygen species inhibit the growth of human hepatocellular carcinoma HepG2 cells. Oncol Lett 11:2145-2151

Merkofer M, Kissner R, Hider RC, Koppenol WH (2004) Redox properties of the iron complexes of orally active chelators CP20, CP502, CP509, and ICL670. Helv Chim Acta 87:3021-3033

Merkofer M, Kissner R, Hider RC, Brunk UT, Koppenol WH (2006) Fenton chemistry and iron chelation under physiologically relevant conditions: electrochemistry and kinetics. Chem Res Toxicol 19:1263-1269

Mishra K, Ojha H, Chaudhury NK (2012) Estimation of antiradical properties of antioxidants using DPPH assay: a critical review and results. Food Chem 130:1036-1043

Moreau C, the FAIRPARK-II study group. et al (2018) Iron as a therapeutic target for Parkinson's disease. Mov Disord 33:568-574

Pearson RG (1963) Hard and soft acids and bases. J Am Chem Soc 85:3533-3539

Perez-Alvarez S, Solesio ME, Manzanares J, Jordan J, Gallindo MF (2009) Lactacystin requires reactive oxygen species and Bax redistribution to induce mitochondria-mediated cell death. Br J Pharmacol 158:1121-1130

Pienaar IS et al (2015a) An animal model mimicking pedunculopontine nucleus cholinergic degeneration in Parkinson's disease. Brain Struct Funct 220:479-500

Pienaar IS et al (2015b) Pharmacogenetic stimulation of cholinergic pedunculopontine neurons reverses motor deficits in a rat model of Parkinson's disease. Mol Neurodegener 10:47

Poewe W, Mahlknecht P (2009) The clinical progression of Parkinson' disease. Parkinsonism Relat Disord 15:S28-32

Rhodes SL, Ritz B (2008) Genetics of iron regulation and the possible role of iron in Parkinson's disease. Neurobiol Dis 32:183-195

Ringbom A (1963) Complexation in analytical chemistry. A guide for the critical selection of analytical methods based on complexation reactions. In: Elving PJ, Kolthoff IM (eds) Chemical Analysis: a series of monographs on analytical chemistry and its applications, 16th edn. Wiley, New York

Savolainen MH, Albert K, Airavaara M, Myöhänen TT (2017) Nigral injection of a proteasomal inhibitor, lactacystin, induces widespread glial cell activation and shows various phenotypes of Parkinson's disease in young and adult mouse. Exp Brain Res 235:2189-2202
Sayre LM, Moreira PI, Smith MA, Perry G (2005) Metal ions and oxidative protein modification in neurological disease. Ann Inst Super Sanita 41:143-164

Sharma P et al (2020) DREADD activation of pedunculopontine cholinergic neurons reverses motor deficits and restores striatal dopamine signaling in parkinsonian rats. Neurotherapeutics. https:// doi.org/10.1007/s13311-019-00830-4 (in press)

Sian-Hülsmann J, Mandel S, Youdim MBH, Riederer P (2011) The relevance of iron in the pathogenesis of Parkinson's disease. J Neurochem 118:939-957

Skoog DA, West DM, Holler FJ, Crouch SR (2000) Analytical chemistry: an introduction, chapter 15, 7th edn. Saunders College Division, Rochester

Sohn YS, Breuer W, Munnich A, Cabantchik ZI (2008) Redistribution of accumulated cell iron: a modality of chelation with therapeutic implications. Blood 111:1690-1699

Sohn YS, Mitterstiller AM, Breuer W, Weiss G, Cabantchik ZI (2011) Rescuing iron-overloaded macrophages by conservative relocation of the accumulated metal. Br J Pharmacol 164:406-418

Sun Y, Pham AN, Waite TD (2018) Mechanism underlying the effectiveness of deferiprone in alleviating Parkinson's disease symptoms. ACS Chem Neurosci 9:1118-1127

Thompson JW, Bruick RK (2012) Protein degradation and iron homeostasis. Biochim Biophys Acta 1823:1484-1490

Tomoda H, Omura S (2000) Lactacystin, a proteasome inhibitor: discovery and its application in cell biology. Yakugaku Zasshi 120:935-949

Wallace DF (2016) The regulation of iron absorption and homeostasis. Clin Biochem Rev 37:51-62

Wang Y et al (2016) Discovery of piperlongumine as a potential novel lead for the development of senolytic agents. Aging (Albany NY) 8:2915-2926

Ward RJ, Dexter DT, Crichton RR (2015) Neurodegenerative diseases and therapeutic strategies using iron chelators. J Trace Elem Med Biol 31:267-273

Watts JC et al (2013) Transmission of multiple system atrophy prions to transgenic mice. Proc Natl Acad Sci USA 110:19555-19560

Workman DG et al (2015) Protection from neurodegeneration in the 6-hydroxydopamine (6-OHDA) model of Parkinson's with novel 1-hydroxypyridin-2-one metal chelators. Metallomics 7:867-876

$\mathrm{Xiao} \mathrm{Y}$ et al (2018) Iron promotes $\alpha$-synuclein aggregation and transmission by inhibiting TFEB-mediatedautophagosome-lysosome fusion. J Neurochem 145:34-50

Yang $\mathrm{H}$ et al (2005) The block of ubiquitin-proteasome pathway induces cell death and the formation of ubiquitin-immunoreactive inclusions in PC12 cells. Zhonghua Shenjing Ke Zazhi 38:430-433

Zhang X, Xie W, Qu S, Pan T, Wang X, Le W (2005) Neuroprotection by iron chelator against proteasome inhibitor-induced nigral degeneration. Biochem Biophys Res Commun 333:544-549

Zhu W et al (2007) Prevention and restoration of lactacystin-induced nigrostriatal dopamine neuron degeneration by novel brain-permeable iron chelators. FASEB J 21:3835-3844

Zhu W et al (2010) Genetic iron chelation protects against proteasome inhibition-induced dopamine neuron degeneration. Neurobiol Dis $37: 307-313$

Publisher's Note Springer Nature remains neutral with regard to jurisdictional claims in published maps and institutional affiliations. 